\title{
LA POLÍTICA EXTERIOR ARGENTINA FRENTE AL VOLÁTIL ESCENARIO INTERNACIONAL DE LA POSTPANDEMIA Y LA COMPETENCIA ENTRE CHINA Y ESTADOS UNIDOS: ¿AQUIESCENCIA, PRAGMATISMO O AUTONOMÍA?*
}

\author{
ARGENTINA'S FOREIGN POLICY AGAINST POST-PANDEMIC VOLATILE \\ INTERNATIONAL SCENARIO AND GROWING COMPETITION BETWEEN CHINA AND \\ THE UNITED STATES. ¿ACQUIESCENCE, PRAGMATISM OR AUTONOMY?
}

Mariano Treacy

\section{RESUMEN}

El escenario internacional actual está caracterizado por tres tendencias centrales: la crisis de la globalización, la confrontación entre los Estados Unidos y China y la crisis del multilateralismo. Debido a esto, existe cierto consenso entre analistas internacionales de que la pandemia, más que causar un cambio drástico en el escenario internacional, provocará una aceleración de estas tendencias. El volátil, incierto y turbulento escenario despierta numerosas preguntas sobre cuál es la mejor manera de pensar una política exterior para la Argentina y de definir estrategias de integración regional en América Latina. Con este objetivo, en este trabajo se ofrece una caracterización de las tendencias dominantes en la escena global actual, se propone una caracterización de la Política Exterior Argentina en el período reciente y se ofrece una reflexión exploratoria sobre el tipo de política exterior que se considera más apropiado en este contexto de incertidumbre.

\section{PALABRAS CLAVE}

Globalización; Crisis; Política Exterior; América Latina; Argentina; Integración Regional

\begin{abstract}
The current international scene is characterized by three central trends: the crisis of globalization, the confrontation between the United States and China and the crisis of multilateralism. Due to this, there is a certain consensus among international analysts that the pandemic, rather than causing a drastic change in the international scene, is going to generate the acceleration of these trends. The volatile, uncertain and turbulent international scene raises many questions about the best way to think about a foreign policy for Argentina and regional integration strategies for Latin America. With this objective in mind, in this work we first offer a characterization of the three dominant trends on the current international scene. Secondly, we propose a characterization of recent foreign policy in Argentina. Finally, we offer an exploratory reflection on the type of foreign policy that is most appropriate for this context of uncertainty.
\end{abstract}

\section{KEYWORDS}

Globalization; Crisis; Latin America; Foreign Policy; Argentina; Regional Integration

\footnotetext{
*El autor agradece los comentarios realizados por Sergio Páez a una versión previa de este artículo.
} 
La política exterior argentina frente al volátil escenario internacional de la postpandemia y la competencia entre China y los Estados Unidos: ¿aquiescencia, pragmatismo o autonomía? DOI: https://doi.org/10.24215/24689912e035

\section{INTRODUCCIÓN}

La Política Exterior Argentina se ha caracterizado en las últimas décadas por haber sufrido los vaivenes propios del famoso péndulo. Lo que en política económica Diamand (1985) describiera como oscilaciones pendulares entre momentos "heterodoxos" y "ortodoxos"1, en política exterior adopta la forma de momentos de orientación "autonomista" y momentos de orientación "globalista" (Simonoff, 2016), "dependiente" (Frenkel y Azzi, 2018) o de aquiescencia (Russel y Tokatlian, 2013). El patrón que se extrae de este movimiento pendular, más allá de la oscilación, es la falta de algunos acuerdos elementales y de políticas de Estado de largo plazo ${ }^{2}$ y esto es lo que podemos observar en líneas generales en nuestro análisis de la política exterior del gobierno de Mauricio Macri y de Alberto Fernández.

El escenario internacional actual está caracterizado por tres tendencias centrales: el estancamiento de la globalización, el enfrentamiento entre Estados Unidos y China y la crisis del multilateralismo. Si bien la pandemia por el COVID-19 ha trastocado todas las proyecciones, estas tendencias ya se habían comenzado a desplegar tras la crisis de 2008. Debido a esto, existe cierto consenso entre algunos analistas que afirman que la pandemia, más que provocar un cambio drástico del escenario internacional, va a generar la aceleración y profundización de estas tendencias (Actis y Creus, 2020; Fiori, 2020; Tokatlian, 2020).

Desde hace más de una década la globalización está atravesando muchas transformaciones que podrían estar expresando un cambio de fase en los ciclos de largo alcance del capitalismo. La slowbalization, como la denomina The Economist (2020), se caracteriza por un estancamiento de los flujos de comercio e inversiones extranjeras que se

\footnotetext{
1 En el modelo de Diamand (1985), los momentos "heterodoxos", liderados por gobiernos populares, tenían un ciclo expansionista caracterizado por el crecimiento de los salarios, del consumo y de la producción industrial doméstica y un ciclo recesivo caracterizado por la crisis del sector externo y el estancamiento económico. En el momento "ortodoxo", guiado por gobiernos liberales, se implementaban medidas de austeridad y disciplina fiscal, se reducía el "costo nacional" (los salarios reales) y se promovían regímenes con beneficios para la llegada de inversiones y mayores niveles de apertura comercial.

2 Como desarrollaremos a lo largo del trabajo, el Mercosur ha sido una de las políticas de Estado sostenidas durante gobiernos de distinto signo político desde su creación en 1991. En este caso las oscilaciones se dan al interior de su seno y se vinculan con la orientación del bloque. En algunos momentos adquiere un carácter más "comercialista" y en otros apunta a una integración más profunda, con creación de instituciones y de mecanismos de integración productiva y de reducción de asimetrías (Kan y Pascual, 2011).
} 
expresa en una reversión de la apertura del sistema de comercio y un flight to quality de los capitales hacia lugares de menor riesgo.

Desde 2008, gobiernos de distinto color político, de diversas regiones y de países con niveles de desarrollo diferentes han implementado de forma creciente medidas proteccionistas. El súmmum de este punto de inflexión ha sido la guerra comercial entre Estados Unidos y la República Popular China, que esconde en realidad una disputa geoestratégica por el liderazgo mundial (Bremmer y Kupchan, 2020).

En los últimos años, se han agudizado las tensiones entre ambas potencias y en la actualidad tanto Washington como Beijing ven con buenos ojos la búsqueda de una mayor autosuficiencia y un recentramiento de su modelo de crecimiento económico. El fortalecimiento del mercado doméstico, en este esquema, ayudaría a disminuir los riesgos geopolíticos. El costo de esta gran transformación es lo que muchos especialistas están denominando como gran "desacople" y describiendo como un ingente desarme de las cadenas globales de valor (Roubini, 2020).

En medio de esta turbulencia, el sistema multilateral expresa las tensiones, incertidumbres y riesgos que se derivan del nuevo escenario y de la crisis de la hegemonía norteamericana. Lo que está en juego en esta situación de extrema volatilidad es en realidad el orden global de la posguerra. Instituciones como la Organización de las Naciones Unidas (ONU), el Banco Mundial (BM), el Fondo Monetario Internacional (FMI) o la Organización Mundial del Comercio (OMC), que reflejan el orden previo, atraviesan una grave crisis.

En la planificación de la política exterior de un país entran en juego algunos elementos vinculados a doctrinas políticas e ideológicas internas, pero también a cuestiones de pragmatismo y búsqueda de alianzas políticas que se vinculan con apuestas de mediano y largo plazo que pueden funcionar o fracasar en función de resultados electorales en otros países. Además de estos elementos, obviamente, también se juegan factores de azar, vinculadas a acontecimientos externos que ocurren más allá de lo que se pueda proyectar, como la pandemia por el COVID-19.

El gobierno de Mauricio Macri ni bien asumió logró la visita del presidente de los Estados Unidos, Barack Obama, y apoyó la candidatura de Hillary Clinton, que proponía una agenda de política exterior más afín al globalismo, al libre comercio y a las instituciones multilaterales. En aquel entonces, se proyectaba una rápida rúbrica del Acuerdo 
La política exterior argentina frente al volátil escenario internacional de la postpandemia y la competencia entre China y los Estados Unidos: ¿aquiescencia, pragmatismo o autonomía? DOI: https://doi.org/10.24215/24689912e035

Transpacífico de Cooperación Económica (TPP), un tratado "megarregional" al que la Argentina se acercaría estrechando vínculos con los países de la Alianza del Pacífico, de un perfil mucho más "liberal" que el Mercosur. Sin embargo, el triunfo de Donald Trump modificó el escenario político internacional, ya que agudizó las tensiones con China, implementó medidas proteccionistas y trató con desdén a las organizaciones multilaterales, privilegiando las negociaciones bilaterales y retirándose de grandes acuerdos regionales y tratados internacionales. El gobierno argentino, pese al cambio de contexto, mantuvo el objetivo de ubicar a la Argentina como un referente regional del libre comercio y apuró un enfriamiento de las relaciones con China, que tuvo que revertir rápidamente. La política exterior de Macri se ubicó más cercana al polo de la aquiescencia, aunque tuvo que mostrar signos de pragmatismo debido a fuertes presiones. Además, apostó fuerte por los espacios multilaterales en un contexto en el que Donald Trump los confrontó abiertamente.

La política exterior de Fernández, si bien desde el plano discursivo quiere acercarse al polo autonomista, se ha vuelto pragmática y medida. La aparición de la pandemia ha trastocado todos los planes del gobierno y la búsqueda de vacunas se ha vuelto la prioridad número uno. El proceso de negociación de la deuda externa ha condicionado el margen de maniobra frente a los Estados Unidos, el principal accionista del FMI. Debido a esto, el gobierno argentino ha buscado mantener una tímida posición equidistante entre esta potencia y China, procurando espacios de complementariedad. La República Popular China continúa siendo uno de los actores externos de más peso para la política doméstica y el gobierno argentino ha demostrado desde el primer momento una posición pragmática en la relación bilateral.

El alza de los términos del intercambio, en un contexto en el que la prioridad es la renegociación de la deuda externa con los acreedores privados y con el FMI, permite proyectar un ingreso mayor de divisas, lo que aportaría un poco más de margen. Además de esto, el triunfo de Joe Biden en 2020, su apuesta por el multilateralismo y una posición mucho más cautelosa en torno al libre comercio ofrecería puntos de acuerdo con la estrategia internacional del Frente de Todos. Si bien se continúa apostando por la consolidación de los mecanismos de integración regional y por el Mercosur, se ha ratificado el apoyo al tratado de libre comercio con la Unión Europea.

El volátil, incierto y turbulento escenario internacional genera muchas preguntas sobre la mejor forma de pensar una política exterior para Argentina y estrategias de integración 
La política exterior argentina frente al volátil escenario internacional de la postpandemia y la competencia entre China y los Estados Unidos: ¿aquiescencia, pragmatismo o autonomía? DOI: https://doi.org/10.24215/24689912e035

regional para América Latina. Con este objetivo es que en este trabajo ofrecemos en primer lugar una caracterización de las tres tendencias dominantes del escenario internacional actual para luego acercar una caracterización de la política exterior de Macri y Fernández en la Argentina observando de qué manera se posicionaron frente a las tendencias identificadas. Finalmente, ofrecemos una reflexión exploratoria sobre el tipo de política exterior que es más adecuada para este contexto de incertidumbre.

Este trabajo de investigación se basa principalmente en la utilización de una metodología mixta que combina el análisis teórico e histórico-estructural con el análisis cuantitativo y con el análisis de la política exterior. Además de la revisión bibliográfica y fuentes primarias y secundarias se revisan documentos y discursos y se trabaja con métodos cuantitativos y análisis estadísticos, para lo que se utilizan las bases de datos WDI (Banco Mundial), WEO (FMI), CEPAL, UNCTADSTAT, OECD y WTO Statistical Review. Para el Análisis de la Política Exterior (APE) se adopta como unidad de análisis el Poder Ejecutivo y se estiman las preferencias de los presidentes y ministros de relaciones exteriores.

\section{ESTANCAMIENTO DE LA GLOBALIZACIÓN Y TENDENCIAS AL DESACOPLE DE LAS CADENAS} DE VALOR

La crisis de 2008 quizás quede en la memoria colectiva y en la historia económica mundial como un punto de inflexión, al igual que otras grandes crisis mundiales como las de 1929 o 1973. El punto en común de todas ellas es que han sido el embrión de las grandes transformaciones del capitalismo (Polanyi, 2011). El escenario abierto por la pandemia abre interrogantes sobre cómo se configurará el post-globalismo y la forma que adoptará, si es que ocurre, el "gran desacople", como algunos analistas han denominado al desarme de la globalización (Roubini, 2020; Smith, 2018).

El sistema internacional enfrenta la incertidumbre que implica atravesar un cambio de ciclo histórico y la paulatina transición hegemónica de los Estados Unidos a la República Popular China. En este escenario, hay quienes sostienen que la globalización es imparable o que la integración de las economías nacionales dificulta la escalada de conflictos bilaterales o multilaterales (Allison, 2017). También existen aquellos que hablan de "tendencias de desacople" o de "globalización desacoplada" (Malamud, 2019) en las economías nacionales, señalando la disminución del comercio internacional de bienes, la 
La política exterior argentina frente al volátil escenario internacional de la postpandemia y la competencia entre China y los Estados Unidos: ¿aquiescencia, pragmatismo o autonomía? DOI: https://doi.org/10.24215/24689912e035

desaceleración de los flujos internacionales de capital y la reaparición de medidas proteccionistas.

Desde 2008, la mayoría de los países han endurecido sus políticas proteccionistas ${ }^{3}$ y el comercio internacional ha crecido a una tasa tres veces menor a la que venía creciendo previo a la crisis, permaneciendo estancado en la relación con la evolución del PBI (Gráfico 1). En la actualidad enfrentamos una de las contracciones del comercio internacional más importantes de las últimas décadas. En 2020, como consecuencia de la pandemia, el comercio mundial cayó un $9 \%$, guiado por una caída en el comercio de servicios $(-16,5 \%)$ y de bienes (-6\%). Esta caída, sin embargo, estuvo desigualmente distribuida, ya que afectó en mayor medida a los países del sur global, donde aún no se verifican signos de recuperación (UNCTAD, 2021).

\section{Gráfico 1. Estancamiento de la Globalización. Comercio mundial de bienes y servicios como \% del PBI. 1970-2020.}

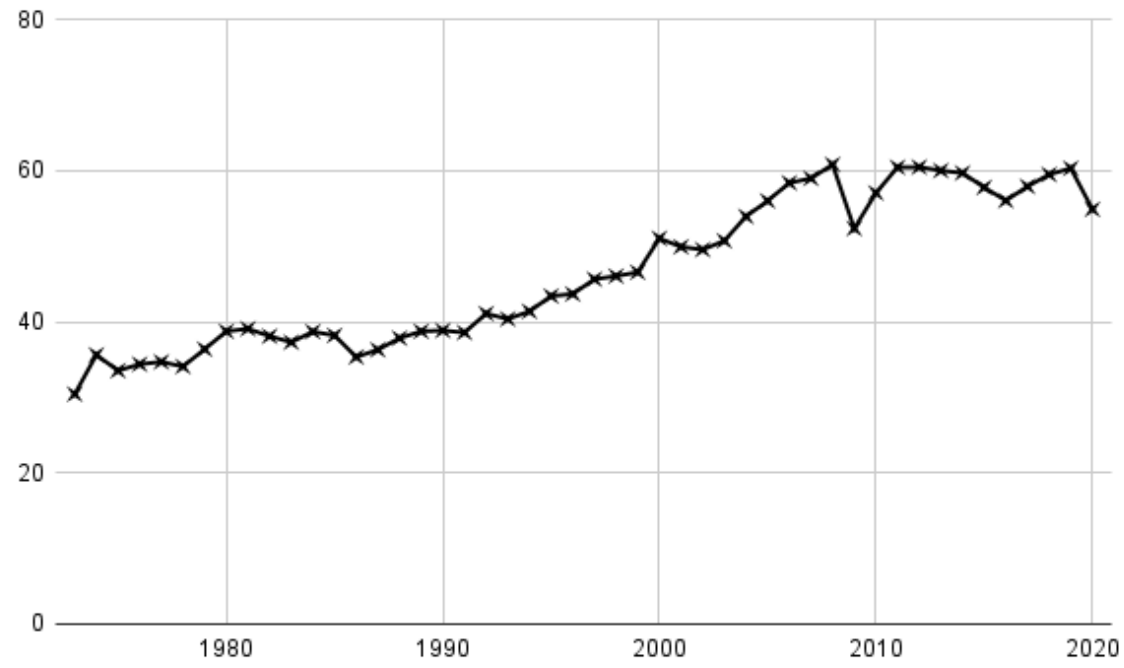

Fuente: elaboración propia con datos de World Bank y OECD

La inversión extranjera directa mundial, por su parte, se derrumbó un $42 \%$ en 2020 , cayendo un 30\% por debajo del mínimo registrado en 2009 luego de la crisis financiera global (Gráfico 2). A diferencia de lo ocurrido con los flujos comerciales, fueron los países del norte global los que más sufrieron el impacto de esta retracción (-69\%). En América

\footnotetext{
${ }^{3}$ La caída de los flujos del comercio se da en un contexto de elevados aranceles a las importaciones, donde alrededor del 7,5\% sufre medidas proteccionistas (Zelicovich y Romero, 2020). En la actualidad los aranceles a las importaciones en los Estados Unidos son los más altos desde 1993.
} 
La política exterior argentina frente al volátil escenario internacional de la postpandemia y la competencia entre

Latina la caída fue del orden del 37\%. China encabezó por primera vez en la historia la clasificación de los mayores receptores de IED, lo que refleja su importancia sobre las cadenas de suministro globales (UNCTAD, 2020).

\section{Gráfico 2. Reversión de los flujos de capital. Flujos netos de inversión extranjera directa como \% del PBI. 1970-2020.}

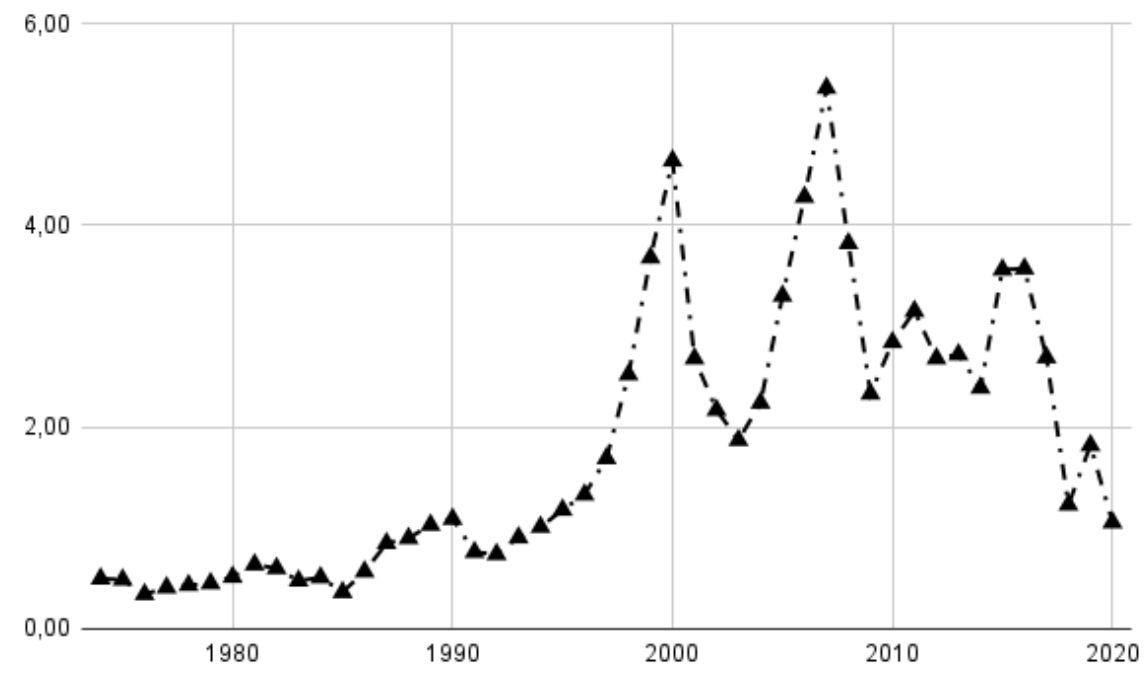

Fuente: elaboración propia con datos del International Monetary Fund, World Bank y OECD.

La integración productiva y financiera entre Estados Unidos y China ha dado forma a la acumulación de capital desde la década de 1980. Estados Unidos ha mantenido un déficit comercial estructural y por cuenta corriente desde 1974 y China representa la mayor parte de ese déficit. En 2018, el 82\% del déficit en cuenta corriente total de EE.UU. provino de un déficit bilateral con China, que ha estado reduciendo sus tenencias de deuda estadounidense pero aún sigue siendo el mayor tenedor con 1,12 billones de dólares (BEA). La internacionalización de la producción ha provocado un incremento de los riesgos geopolíticos en el corazón de la acumulación del capital y por eso se está volviendo a hablar, como en la década del '30, del desacople.

El escenario general de este proceso en tensión con la globalización es la disputa por la hegemonía entre los Estados Unidos y China. La principal hipótesis según la cual no estallaría un conflicto armado es que, a diferencia de otras disputas hegemónicas, en la actualidad las economías china y estadounidense están altamente integradas. El desarme de cadenas globales de valor, al menos por el momento, se daría principalmente en la 
La política exterior argentina frente al volátil escenario internacional de la postpandemia y la competencia entre

fabricación de componentes tecnológicos e insumos clave como semiconductores o procesadores para el desarrollo de la inteligencia artificial, las redes 5G y la computación cuántica (Bremmer y Kupchan, 2020).

El estancamiento del comercio internacional, la reversión de los flujos de capitales transnacionales y un incipiente proceso de relocalización productiva podrían estar anunciando una nueva división internacional del trabajo en la que se reorientarían algunos fragmentos de las cadenas de suministro hacia zonas más cercanas a las costas estadounidenses o más seguras en términos geopolíticos. La relocalización podría beneficiar a países como Vietnam o la India, más estables y con mayor afinidad política con los Estados Unidos (Johnson y Gramer, 2020).

Este cambio de ciclo podría implicar la transformación de la globalización vinculada a formas transnacionalizadas y desterritorializadas de la producción y a la financiarización. La "post-globalización" estaría caracterizada por la "fragmentación y la reorganización de los mercados y las cadenas productivas de la etapa anterior y, al mismo tiempo, por una mayor integración de la economía digital” (Sanahuja, 2020, p. 84).

\section{LA DISPUTA HEGEMÓNICA ENTRE ESTADOS UNIDOS Y CHINA}

La pandemia ha puesto en evidencia la crisis de dos de las grandes verdades que forjaron la narrativa histórica de los últimos tiempos: la de la globalización neoliberal en tanto respuesta de dominación y acumulación y la de Estados Unidos en el centro del sistema de poder internacional (Grigera, 2020).

Luego de un brevísimo interregno de multipolaridad ${ }^{4}$ nos encontramos nuevamente en un escenario de creciente bipolaridad entre Estados Unidos y China (Sanahuja, 2020). En el esquema bipolar que se está comenzando a vislumbrar, a diferencia del que existía en la época de la Guerra Fría, las economías de las dos superpotencias se encuentran sumamente articuladas y experimentan una dependencia recíproca ${ }^{5}$.

\footnotetext{
${ }^{4}$ El ascenso de potencias emergentes como los BRICS (Brasil, Rusia, India, China y Sudáfrica) en los 2000 no ha logrado consolidar un esquema real de gobernanza global multilateral.

${ }^{5}$ Existen muchos indicadores de reciprocidad y muchos autores definen a esta relación como una alianza estratégica en la que China logra exportar lo que produce y EE.UU. sostiene artificialmente su nivel de consumo a través del acceso a bienes más baratos y al endeudamiento público y privado (Arceo, 2018). Además de la interdependencia comercial existe una articulación productiva, ya que en China se producen muchas de las partes, piezas, componentes e insumos de bienes estratégicos para los Estados Unidos.
} 
La política exterior argentina frente al volátil escenario internacional de la postpandemia y la competencia entre China y los Estados Unidos: ¿aquiescencia, pragmatismo o autonomía? DOI: https://doi.org/10.24215/24689912e035

La reorganización del mundo que tuvo lugar entre 1980 y la crisis de 2008 bajo la hegemonía estadounidense convirtió a Asia oriental en un centro de acumulación de capital global con China en su epicentro (Panitch y Gindin, 2015). Durante muchos años, la fragmentación y reubicación de la producción, la configuración de las cadenas de valor globales y la consolidación del dólar como reserva de valor global y de China como principal acreedor mundial configuraron una relación de beneficio mutuo y profundizaron la integración productiva y financiera entre ambos países. Esta articulación permitió a China mantener cierta autonomía geopolítica de los intereses estadounidenses y ascender, en los últimos años, como un "Estado contendiente" (Fusaro, 2017).

En el transcurso de pocas décadas, China pasó de ser la meca industrial de las inversiones extranjeras en bienes manufacturados de bajo valor agregado con bajos costos salariales a ser un centro global de investigación y desarrollo tecnológico, exportador de productos y servicios complejos, y uno de los principales emisores de inversión extranjera. Aunque Estados Unidos aún mantiene su supremacía, el ascenso de China redujo considerablemente la brecha entre los dos países (Zhao, 2019).

La interdependencia económica entre China y Estados Unidos se está revirtiendo en un movimiento que algunos analistas caracterizan como "el gran desacople" (Actis y Creus, 2019; Bremmer y Kupchan, 2020; Carreiras y Malamud, 2020). Este proceso podría revertir lentamente la integración entre los dos países y aumentar la probabilidad de conflicto ya que Estados Unidos teme perder su hegemonía económica y militar. Sin embargo, el tamaño del mercado interno chino y las ventajas de la eficiencia en las cadenas de suministro globales limitan el traslado de algunas actividades manufactureras fuera del país (Orr, 2018).

El ascenso de China representa una amenaza sistémica a la hegemonía estadounidense ya que compite por los recursos naturales y minerales, por el control de flujos comerciales y la gestión y el acceso a rutas y puertos comerciales, por el desarrollo de activos cruciales como el conocimiento y la innovación, y por la infraestructura asociada, como las redes de comunicación y las capacidades informáticas (Woodward, 2017; Treacy, 2021). Tanto Washington como Beijing han comenzado a impulsar grandes proyectos geoestratégicos de integración para disminuir riesgos geopolíticos (Smith, 2018). El más importante de estos proyectos probablemente sea el de la Nueva Ruta de la Seda (BRI), que será definitivo a la hora de evaluar la capacidad de China de asumir mayores compromisos internacionales en 
La política exterior argentina frente al volátil escenario internacional de la postpandemia y la competencia entre China y los Estados Unidos: ¿aquiescencia, pragmatismo o autonomía? DOI: https://doi.org/10.24215/24689912e035

el futuro. Beijing apuesta a una estrategia de ascenso pacífico $0^{6}$ y paulatino con miras al 2049, año en el que se cumplirán 100 años de la Revolución y fecha para la que se espera que se materialice el "sueño chino". En el marco de su ascenso, China ha experimentado una creciente necesidad de fuentes extranjeras de materias primas (soja, madera), minerales (cobre, estaño, mineral de hierro, platino, aluminio) y energía (petróleo, carbón). Esta necesidad ha configurado sus relaciones internacionales y estrategias de política exterior, promoviendo una activa política de internacionalización de sus empresas.

\section{Crisis del multilateralismo}

La crisis de la hegemonía de los Estados Unidos y del orden internacional liberal ha agudizado la parálisis de las instituciones multilaterales. Según Malacalza y Hirst (2020), el multilateralismo se encuentra amenazado por el ascenso de partidos de nacionalistas, globalifóbicos y de derecha, pero va a sobrevivir. Ni los Estados Unidos ni China habían manifestado un interés específico en la agenda multilateral (al menos hasta el triunfo de Biden). Sin embargo, la pandemia le ha dado una sobrevida tanto a la OMS como a la OMC, que han vuelto a estar en la agenda de los principales líderes políticos del mundo.

La Organización Mundial de la Salud (OMS) ha demostrado tener un impacto concreto en la gestión de la pandemia, aunque ha sido fuertemente torpedeada por la disputa entre ambas potencias, llegando al extremo de sufrir el desfinanciamiento y el retiro de los Estados Unidos en plena crisis epidemiológica mundial. Pese a esto, su labor puso en evidencia la importancia de un espacio multilateral, pero también la debilidad de estos espacios para gobernar y proveer bienes públicos globales como vacunas ${ }^{7}$ (Malacalza y Hirst, 2020).

Precisamente, ha sido la discusión sobre las vacunas la que ha reactivado las presiones en el seno de la Organización Mundial del Comercio (OMC), otra de las instituciones

\footnotetext{
${ }^{6}$ Pese a su mesura histórica, en los últimos meses la diplomacia china ya ha elevado su tono y ha pasado a ser más confrontativa que en el pasado. La apuesta de Washington se concentra en mantener la supremacía del dólar y el control naval de los mares y océanos del mundo, creando círculos concéntricos de control alrededor de China para contener su expansión (Fiori, 2020).

7 Uno de los principales desafíos que presenta el ascenso de China es el de la llamada "Trampa de Kindleberger", que refleja la ausencia de una potencia líder que asuma el rol de proveedor de bienes públicos globales en un contexto de transición hegemónica. En la 73a Asamblea Anual de la Organización Mundial de la Salud (OMS) realizada virtualmente en mayo de 2020 el primer mandatario chino Xi Jinping ha declarado que la vacuna china de COVID-19 sería un bien público global cuando estuviera disponible. Al momento del envío de este trabajo todavía no lo había hecho, pero sí acompañó el pedido de liberación de patentes que hicieron Sudáfrica y la India en la OMC, que recogió el apoyo de Estados Unidos, Rusia y Francia.
} 
La política exterior argentina frente al volátil escenario internacional de la postpandemia y la competencia entre China y los Estados Unidos: ¿aquiescencia, pragmatismo o autonomía? DOI: https://doi.org/10.24215/24689912e035

multilaterales que se encontraba en estado crítico $^{8}$. El ingreso de China a la OMC en 2001 y su reconocimiento por parte de la comunidad internacional como "economía de mercado" aceleró un proceso que tuvo su punto de inflexión luego de la crisis de 2008. A partir de entonces la OMC entró en una parálisis casi absoluta (Okonjo-Iweala, 2020) y Estados Unidos, que había sido su principal impulsor, le fue quitando prioridad reorientando su estrategia hacia acuerdos bilaterales y megarregionales ${ }^{9}$.

Si bien la crisis del multilateralismo se puede rastrear desde hace más de una década, en los últimos años ha quedado en evidencia debido a la proliferación de medidas proteccionistas, el bloqueo del órgano de apelaciones del mecanismo de resolución de controversias de la OMC o las limitaciones a la administración del comercio en el marco de la guerra comercial entre las dos potencias (Zelicovich y Romero, 2020).

\section{LA POLÍTICA EXTERIOR DE WASHINGTON FRENTE A LAS GRANDES TENDENCIAS}

En Estados Unidos, durante la Administración de Donald Trump, impulsó la estrategia de "America First", consistente en un ataque frontal al multilateralismo y la implementación de un programa de políticas proteccionistas.

El ataque al multilateralismo se expresó, entre otras cosas, en una desfinanciación de la OMS en plena pandemia y el retiro del país de Tratados Internacionales como el Acuerdo de París sobre el cambio climático. También se tradujo en cierto desdén de la importancia

8 Con la India y Sudáfrica a la cabeza, una coalición de países ha presentado un documento solicitando a la OMC la suspensión temporal de derechos de propiedad intelectual sobre productos médicos relacionados con el coronavirus para que las vacunas genéricas puedan fabricarse rápidamente en las plantas locales. Si bien la propuesta inicial era más amplia y abarcaba la posibilidad de suspender la propiedad intelectual, el copyright, la información no divulgada y los diseños industriales de respiradores y máscaras, por el momento solo se lograron algunos pronunciamientos públicos para suspender solamente las patentes, que han suscitado una fuerte resistencia por parte de los grandes laboratorios farmacéuticos.

${ }^{9}$ Sin lograr avanzar en la agenda del desarrollo de la Ronda de Doha, y lejos de abandonar sus pretensiones, los países desarrollados quisieron impulsar la ampliación de la OMC incluyendo "nuevos temas comerciales" como políticas de competencia, compras gubernamentales, inversión, servicios, comercio electrónico, derechos de propiedad intelectual, etc. Como respuesta, algunos países como la India y Brasil plantearon que ya no darían más acceso a mercados si no se avanzaba con la agenda de reducción de los subsidios agrícolas y de aranceles en los países desarrollados, lo que llevó a un bloqueo de las negociaciones y a su estancamiento alrededor de 2008. La estrategia de las corporaciones y de los países desarrollados se ha orientado desde entonces a dar por finalizada la Ronda de Doha para poder tener mandato de incluir "nuevos temas" en la OMC pero principalmente en otros tratados comerciales, sean estos "megarregionales" (plurilaterales) como el TPP (actual CPTPP), TTIP, el RCEP, tratados bilaterales (como los TLC o los Acuerdos de Asociación), o acuerdos específicos sobre bienes tecnológicos, sobre bienes medioambientales 0 sobre Servicios (TISA), etc. 
La política exterior argentina frente al volátil escenario internacional de la postpandemia y la competencia entre China y los Estados Unidos: ¿aquiescencia, pragmatismo o autonomía? DOI: https://doi.org/10.24215/24689912e035

de la Organización Mundial del Comercio y la Organización del Tratado del Atlántico Norte (OTAN). La implementación de políticas proteccionistas, por su parte, consistió en la salida y/o renegociación de los acuerdos comerciales (TPP, TTIP, TLCAN), la introducción de aranceles y medidas no arancelarias y el impulso de acuerdos bilaterales desde el Departamento de Comercio de los EEUU (USTR) para reducir el déficit comercial con China, México, Japón, Vietnam y Corea del Sur, entre otros. En este programa también se buscó relocalizar actividades productivas en suelo norteamericano para revertir el déficit comercial y mejorar la situación del empleo local (Jeffers, 2021).

La reciente transición política hacia la administración demócrata de Joe Biden ha mostrado rasgos de continuidad en lo que respecta a la política exterior de Trump, aunque también se vislumbran una serie de rupturas. En este marco, se espera una nueva apuesta por el multilateralismo y el reingreso de los Estados Unidos a la OMS y a acuerdos internacionales como el Tratado de París (Campanella, 2020; Ward, 2021; Haas, 2021). En el marco de las continuidades, se espera que se sostengan medidas proteccionistas (con aranceles más selectivos y controles a las exportaciones) y la confrontación con China ${ }^{10}$ y Rusia debido a la disputa por el liderazgo global y de las tensiones geopolíticas en regiones clave. También mantendría una postura firme con respecto a la situación política en Ucrania, Israel, Afganistán y Venezuela11. Además de esto ya se ha impulsado el plan "Buy American" de compra de productos nacionales.

Hay quienes afirman que, en el marco de estas continuidades, se está consolidando un nuevo orden post-neoliberal (Lissardy, 2021), un nuevo consenso en la política norteamericana que identifica que la apertura económica internacional de las últimas décadas ha sido imprudente ya que ha perjudicado a los trabajadores nacionales e incrementado la desigualdad económica (Posen, 2021). En el marco de este orden postneoliberal, Trump representaría una versión de derecha (etnonacionalista, antidemocrática y

10 Biden mantuvo aranceles y controles de exportaciones de insumos clave y continúa enviando buques de guerra al Mar de China Meridional. Además, mantuvo vínculos diplomáticos estrechos con Taiwán y denunció a China por la violación de derechos humanos en Hong Kong y Xinjiang, en donde se produjo la represión de uigures, una minoría étnica musulmana (Haas, 2021). Además de esto, uno de los principales objetivos de la administración será contrarrestar las prácticas desleales chinas (GENCl, 2021)

11 Sin ir más lejos, el gobierno de Joe Biden, como el de Trump, desconoce a Maduro como presidente legítimo de la República Bolivariana de Venezuela y reconoce en su lugar a Juan Guaidó, un dirigente de la oposición que se autoproclamó presidente encargado en 2019. El "embajador" de Guaidó en Washington Carlos Vecchio fue invitado en enero de 2021 a la toma de posesión de Biden (La Vanguardia, 2021) 
La política exterior argentina frente al volátil escenario internacional de la postpandemia y la competencia entre China y los Estados Unidos: ¿aquiescencia, pragmatismo o autonomía? DOI: https://doi.org/10.24215/24689912e035

con tendencia al autoritarismo) y Biden una versión de izquierda (tomando principalmente la agenda social y laboral y la agenda ambiental con el Green New Deal) (Marantz, 2021).

China, por su parte, sigue manteniendo el pragmatismo de su sistema económico y de su programa de apertura y adquiriendo crecientemente un mayor protagonismo en el escenario internacional. Sus políticas son de largo plazo y continúan apoyándose en planes quinquenales bajo la dirección centralizada del Partido Comunista Chino, lo que produce una menor volatilidad política en el corto plazo que dota de coherencia y continuidad a los lineamientos adoptados. La principal disputa de Beijing consiste en redefinir las instituciones del orden de posguerra para adaptarlas a la situación geopolítica actual para que se refleje en la gobernanza global su mayor e indiscutible protagonismo.

En este marco ha preferido el bilateralismo al multilateralismo y continúa liderando el impulso de la Asociación Económica Integral Regional (RCEP) ${ }^{12}$, el Área de libre comercio del Asia Pacífico (FTAAP), impulsando tratados de libre comercio con Noruega, Singapur, Mongolia, Nueva Zelanda, Mauricio y los Países de Europa Central y Oriental (PECO) y otros acuerdos con la Unión Europea e Irán (GENCI, 2021). La más importante de estas iniciativas es la Nueva Ruta de la Seda (BRI), un proyecto destinado a desarrollar seis corredores terrestres y marítimos para ampliar la integración económica y política de Asia con Oriente Medio, Europa, África y América Latina ${ }^{13}$. A través de la construcción de infraestructura, la apertura de mercados y la realización de inversiones, se espera que la $\mathrm{BRI}$ proyecte los intereses chinos y fortalezca su influencia política y cultural en todo el mundo, a la vez de salvaguardar sus áreas fronterizas y asegurar un acceso geoestratégico a depósitos minerales, petróleo, tierra, mercados e influencias (Rousset, 2018).

La competencia geopolítica por el liderazgo entre Estados Unidos y China, un entorno de instituciones multilaterales paralizadas y una economía internacional que no se repone de la crisis de 2008 forman parte del complejo escenario en que se ha desenvuelto la política exterior argentina de los últimos años.

\footnotetext{
${ }^{12}$ En los últimos meses trascendió la noticia de que el gobierno de China, aprovechando el repliegue de los Estados Unidos, está negociando su ingreso al Comprehensive and Progressive Trans-Pacific Partnership (CTPP), un acuerdo que en su momento había sido creado precisamente para excluir a la potencia asiática y contrarrestar su peso geopolítico (Bloomberg, 2021)

${ }^{13}$ Esta iniciativa incluye inversiones en todos los sectores (desde turismo a minería, electrónica y energía solar), la creación de parques industriales y áreas portuarias, grandes obras públicas (ferrocarriles, puentes, túneles, presas) y equipos de energía (oleoductos y gasoductos, centrales eléctricas, campos eólicos).
} 


\section{LA POLÍTICA EXTERIOR ARGENTINA: ENTRE LA AQUIESCENCIA, EL PRAGMATISMO Y LA BÚSQUEDA DE UNA MAYOR AUTONOMÍA}

La política exterior argentina de las últimas décadas ha oscilado entre estrategias basadas en la lógica de la autonomía y estrategias basadas en la lógica de la aquiescencia (Russell y Tokatlian, 2013), que implican una mirada globalista (Simonoff, 2016). El movimiento entre estos dos polos, si bien implica una oscilación pendular, también ha estado condicionado por algunos factores estructurales vinculados al carácter periférico que ocupa nuestro país y la inserción subordinada de nuestra región en el sistema internacional.

La lógica de la aquiescencia, que porta una mirada globalista, reconoce la condición subordinada de América Latina en el sistema internacional y persigue como estrategia de política exterior complacer a la potencia hemisférica de occidente, los Estados Unidos, con la expectativa de obtener algún rédito material o simbólico y contar con su aprobación para sostener la coalición en el poder (Russell y Tokatlian, 2013). Esta orientación de la política exterior busca mejorar las condiciones internas de acumulación renunciando a algunos espacios de soberanía acoplándose a los intereses de los Estados Unidos ${ }^{14}$ y privilegiando las relaciones Norte - Sur con los tradicionales socios de Occidente. Uno de los ejes centrales de la lógica de aquiescencia es la no adhesión a esquemas de integración regional profunda que puedan afectar el vínculo estrecho con Washington (Russell y Tokatlian, 2013). La estrategia de integración regional con los países vecinos, por lo tanto, pasa a ser subsidiaria de mantener una buena relación con los Estados Unidos y sus aliados (Simonoff, 2020).

La lógica autonomista de política exterior busca el desarrollo económico, la paz, la extensión del alcance geográfico de las relaciones exteriores, la restricción del poder de las grandes potencias y la construcción de un orden internacional más equitativo. Para lograr estos objetivos se suele apostar al regionalismo, a los organismos multilaterales, al derecho internacional y al soft power (Russell y Tokatlian, 2013). En esta lógica se suelen establecer algunas estrategias que buscan incrementar los márgenes de maniobra restringiendo el

\footnotetext{
${ }^{14}$ La voluntad de plegarse a las potencias no necesariamente obedece a los intereses de las élites, sino que muchas veces puede deberse a cuestiones de otro orden, como puede ser la seguridad nacional o la necesidad de un mercado de destino de las mercaderías o de un prestamista para desarrollar inversiones. En algunos casos, sobre todo en muchos países de Centroamérica y el Caribe, puede incluso ser la única estrategia viable.
} 
La política exterior argentina frente al volátil escenario internacional de la postpandemia y la competencia entre China y los Estados Unidos: ¿aquiescencia, pragmatismo o autonomía? DOI: https://doi.org/10.24215/24689912e035

abuso de poder de las grandes potencias ${ }^{15}$, diversificando los lazos externos, fortaleciendo la unidad colectiva regional y/o evitando compromisos militares en conflictos armados. Debido a esto, las miradas autonomistas suelen priorizar las relaciones Sur-Sur, ya sea con las potencias emergentes (China, Rusia, India, Sudáfrica) o con países vecinos, especialmente los del Mercosur (Brasil, Uruguay y Paraguay). Bajo esta mirada se busca una inserción virtuosa en las redes globales, pero priorizando los intereses nacionales.

Una política exterior adecuada debería aggiornar su doctrina o su ideología y dar cuenta del contexto internacional y regional en el que se desenvuelve, identificando los condicionantes internos y externos y los medios de acción y alianzas que se pueden construir. Adoptar alguno de los dos polos de forma acrítica, sea el de la lógica autonomista o el de la lógica de aquiescencia, puede conllevar consecuencias negativas para la soberanía del país.

El mundo que se configuró con el ascenso de China planteó un parteaguas estructural para los condicionantes de la política exterior de la Argentina que se verifica en un nuevo mapa de alianzas estratégicas donde el país asiático se sumó a Brasil y los Estados Unidos a la mesa de socios estratégicos. Cualquier estrategia de política exterior debería contemplar este como un factor estructural (y estructurante) de las relaciones internacionales del país.

A su vez, la crisis de 2008 ha abierto una nueva fase en la acumulación global, donde los espacios multilaterales han cedido prioridad frente a las negociaciones bilaterales y megarregionales. En los últimos años, además, el ascenso de China ha provocado una nueva oleada de medidas proteccionistas en los países más fuertes de Occidente. Una lectura acrítica de los tratados de libre comercio y de la supremacía de los espacios multilaterales como ámbitos de negociación, por lo tanto, también puede llevar a resignar espacios de soberanía.

\section{La política exterior de “CAmbiemos” ¿error de diagnóstico, Ceguera IDEOLÓGICA O PACTO EMPOBRECEDOR?}

La alianza Cambiemos, el partido que llevó a ocupar la Presidencia de la Nación entre 2015 y 2019 al Ingeniero Mauricio Macri, asumió el gobierno con el objetivo de "insertar adecuadamente" a la Argentina en el mundo, partiendo de nuestra "identidad occidental"

\footnotetext{
${ }^{15}$ Que se busque evitar un abuso de poder no implica necesariamente una confrontación sistemática ni que no puedan encontrarse agendas comunes para el trabajo diplomático bilateral.
} 
La política exterior argentina frente al volátil escenario internacional de la postpandemia y la competencia entre China y los Estados Unidos: ¿aquiescencia, pragmatismo o autonomía? DOI: https://doi.org/10.24215/24689912e035

mediante una convergencia del Mercosur con la Alianza del Pacífico y el fortalecimiento de "nuestras tradicionales relaciones con Europa y EEUU" 16 (Grupo Consenso, 2015, p. 3).

En palabras del expresidente, su estrategia podría resumirse en la frase "queremos volver a ser parte del mundo y cortar con el aislacionismo", pronunciada en 2016 en la reunión anual de la Clinton Global Initiative (Macri, 2016b, párr. 2). El objetivo de reinsertarse en el mundo se vinculó con la estrategia de que la Argentina lidere en la región una transición "postprogresista" aprovechando la fuerte crisis interna que estaba experimentando Brasil con el impeachment a Dilma Rousseff y la inestabilidad e impopularidad del gobierno interino de Michel Temer.

La política exterior del gobierno de Cambiemos se basó en cinco ejes programáticos: 1) Jerarquizar los vínculos con Estados Unidos y países de Europa Occidental como Alemania, España, Italia, Gran Bretaña y Holanda; 2) Mejorar las relaciones con los organismos multilaterales de crédito (FMI, Banco Mundial) y otros espacios multilaterales (OMC, G-20); 3) Mejorar las relaciones con el sector financiero internacional y las empresas transnacionales; 4) Aislar a Venezuela y reorientar los mecanismos de integración regional hacia la Alianza del Pacífico; 5) Quitarle jerarquía a las relaciones con China y Rusia (Busso, 2019).

Desde la campaña electoral, Macri había instalado la idea de una Argentina aislada del mundo, de las corrientes de inversiones y de sus socios históricos. Para congraciarse con la comunidad financiera internacional y bajo la promesa de una prominente "lluvia de inversiones", las primeras medidas económicas que se tomaron fueron la apertura de la cuenta capital, el levantamiento del control de cambios, la reducción de retenciones a las exportaciones y el pago de los juicios perdidos en el Centro Internacional de Arreglo de Diferencias Relativas a Inversiones (CIADI) y a los holdouts por la reestructuración de la deuda externa, dando inicio a un nuevo ciclo de endeudamiento externo (Pascual y Ghiotto, 2019).

16 Los lineamientos de la Política Exterior de Cambiemos se encuentran identificados en el documento "Reflexiones sobre los desafíos externos de la Argentina: Seremos afuera lo que seamos adentro" publicado en abril de 2015 por el Grupo Consenso. Entre otros referentes, este documento fue firmado por Jorge Faurie (quien luego sería Canciller), Fulvio Pompeo (quien sería secretario de Asuntos Estratégicos) y Diego Guelar (quien sería Embajador de la Argentina en la República Popular China). 
La política exterior argentina frente al volátil escenario internacional de la postpandemia y la competencia entre

Con respecto a las relaciones bilaterales, el memorándum con Irán por la Causa Amia, la relación con China, Cuba y Venezuela y el proteccionismo del Mercosur fueron utilizados para darle un sentido a la narrativa de una Argentina aislada del mundo. Según su perspectiva, el posicionamiento "ideológico" de la política exterior del kirchnerismo habría llevado a un largo derrotero de fracasos que dejaron un país fracturado, sin crecimiento, aislado del mundo y al borde de convertirse en Venezuela, una metáfora que representaba (y lo sigue haciendo para gran parte del arco político y de la sociedad) la concentración de todos los males de la República.

El mundo lo ve con mayor contundencia porque a la distancia se veía un país que iba en la dirección del desastre final, el desastre final sería un Venezuela, un país totalmente aislado del mundo, sin energía, sin servicios, con una crisis humanitaria bestial donde enfermedades que ya habían desaparecido como un peligro, vuelven, a un país que giró en la dirección correcta y que ve que, claramente, ha tenido que aguantar muchos chubascos porque la herencia era muy pesada, pero lo ve persistir (Macri, 2019, párr. 10 ).

En contraste con esta tendencia, la idea de "volver al mundo" y de "desideologizar las relaciones exteriores" consistía en posicionar a la Argentina como líder regional, faro del libre comercio, retomar las relaciones con los socios occidentales como Estados Unidos y la Unión Europea y apostar por el multilateralismo (Frenkel y Azzi, 2018). En su discurso de inauguración de las sesiones ordinarias del Congreso en marzo de 2016 el presidente Macri afirmó que en tres meses de gobierno "restablecimos relaciones con los Estados Unidos, Francia, Italia, Inglaterra, Alemania e Israel, luego de años de conflictos, diferencias o a veces simplemente negligencias" (Macri, 2016ª̣, párr. 26).

El nombramiento de la respetada Susana Malcorra como Ministra de Relaciones Exteriores (y su posterior postulación a la Secretaría General de la ONU), la organización del Foro Mini-Davos (2017), la Conferencia Ministerial de la OMC ${ }^{17}$ (2017), la Cumbre del G-20 (2018) y la firma del acuerdo entre el Mercosur y la Unión Europea (2019) intentaron proyectar la imagen de un gobierno que buscaba activamente el beneplácito de los

17 La 11a Cumbre Ministerial de la OMC Buenos Aires pasará tristemente a la historia por varias razones. En primer lugar, se le prohibió el ingreso a académicos y activistas locales e internacionales violando todo protocolo en una causa que actualmente está caratulada como Espionaje llegal por parte de la Agencia Federal de Inteligencia (AFI). Además de esto, no se logró cerrar una declaración final y la delegación de Estados Unidos se retiró antes de finalizada la cumbre, en una clara muestra del desprecio hacia el espacio multilateral. 
La política exterior argentina frente al volátil escenario internacional de la postpandemia y la competencia entre China y los Estados Unidos: ¿aquiescencia, pragmatismo o autonomía? DOI: https://doi.org/10.24215/24689912e035

mercados y de los países líderes de occidente, retomando la "normalidad" de sus relaciones internacionales y priorizando los espacios de deliberación multilaterales.

En el mundo hay una corriente de cuestionamientos. Esto genera una cierta ruptura en lo que es el liderazgo tradicional. Esto de cerrarse, de mirar sólo para adentro, nunca condujo al mundo a un periodo de crecimiento o a resultados positivos. Nosotros creemos en un mundo abierto, integrado, una Argentina que se proyecta hacia el mundo, porque hemos visto, desde nuestra propia experiencia en el país, que cerrarse no dio resultado. (Malcorra, 2017, párr. 3)

La relación con el Mercosur estuvo fijada como un medio para llegar, mediante acuerdos de libre comercio con la Alianza del Pacifico y con la Unión Europea, a los mega acuerdos regionales de libre comercio (los TPP y TTIP), que venían siendo impulsados por los Estados Unidos antes del triunfo de Trump (Simonoff, 2020). Esta apuesta se dio por fuera de los ámbitos multilaterales y manifestó una clara intención de congraciarse con los Estados Unidos, aunque esto significara tensar las relaciones con China y caminar hacia una flexibilización del Mercosur.

La firma del acuerdo de libre comercio con la Unión Europea en 2019 cristalizó la visión del bloque regional como puente hacia la hiperglobalización ${ }^{18}$, incluso si eso implicaba ceder espacios de soberanía y perjudicar al sector industrial de la región. Esta idea, compartida por Macri y Bolsonaro, está en el corazón de la lógica de la aquiescencia y se resume en la categoría de "Mercosur para el Siglo XXI" que el expresidente utilizó en varios de sus discursos.

Necesitamos una puesta al día del Mercosur, necesitamos un Mercosur para el siglo XXI. Necesitamos que nuestro proyecto de integración sea un instrumento de vanguardia donde las decisiones que tomemos tengan en cuenta la dinámica de cambios regionales y globales. (Macri, 2017b, parr. 3)

La idea de un "bloque moderno" y de una "integración inteligente" se hizo mediante una construcción simbólica que apuntó a asociar la apertura con el progreso, el dinamismo y la competitividad en una clara contraposición ideológica a la construcción de un supuesto Mercosur vetusto, oxidado, proteccionista y atrasado propio de la administración anterior.

${ }^{18}$ Como señalan Ghiotto y Echaide (2020), la firma del TLC entre el Mercosur y la Unión Europea no se basó en ningún estudio de impacto que le diera consistencia científica. 
La política exterior argentina frente al volátil escenario internacional de la postpandemia y la competencia entre China y los Estados Unidos: ¿aquiescencia, pragmatismo o autonomía? DOI: https://doi.org/10.24215/24689912e035

En esta construcción del proyecto regional se priorizó una mirada aperturista de regionalismo que postuló el abandono de las pautas proteccionistas como camino de desarrollo. El giro político que representó el gobierno de Cambiemos habilitó una visión de la integración regional en la que la autonomía perdió relevancia y en donde el Mercosur pasó a pensarse en un sentido de reorientación de sus vínculos hacia la Unión Europea, los Estados Unidos y la Alianza del Pacífico (Miguez, 2017).

El gobierno de Cambiemos planteó un rescate de la lógica de aquiescencia y del acoplamiento a los Estados Unidos como horizonte de su política exterior (Busso, 2019). El triunfo de Donald Trump sobre Hillary Clinton en noviembre de 2016, sin embargo, modificó repentinamente el tablero de juego y dejó al gobierno argentino sin una clara estrategia por fuera de lo que sería alinear su política a los intereses de la política exterior norteamericana. El cambio de administración conllevó un viraje de la política exterior norteamericana que consolidó las tendencias que se venían observando desde 2008 al cuestionamiento del multilateralismo e inauguró una nueva etapa de repliegue de la globalización y guerra comercial con China en el marco de la disputa por el liderazgo global.

En esta búsqueda de congraciarse con la potencia del norte, uno de los ejes fue la confrontación permanente con Venezuela, el desmantelamiento de toda la institucionalidad heredada de los tiempos de la marea rosa y el acercamiento a instituciones más afines a los intereses norteamericanos como la OEA, el Grupo de Lima o PROSUR (Rocha Valencia, 2021). La suspensión de Venezuela del Mercosur, la salida de Argentina de la UNASUR, el vaciamiento de la CELAC, el acercamiento a la Alianza del Pacífico, también dieron muestras de ello (Pignatta, 2020).

La relación entre Argentina y el Fondo Monetario Internacional se volvió uno de los temas más importantes de la agenda bilateral con los Estados Unidos. En el mes de noviembre de 2018, en el marco de la visita de Donald Trump a la Argentina para la cumbre del G-20, Mauricio Macri le agradeció especialmente por el apoyo brindado para que la Argentina lograra la asistencia financiera del FMI (Macri, 2018). El préstamo que se pidió al Fondo Monetario Internacional también puede ser leído desde la lógica de la aquiescencia.

El gobierno de Macri buscó complacer a los Estados Unidos realineando su política exterior a sus intereses hemisféricos y consiguió a cambio que el FMI le otorgue el préstamo más 
La política exterior argentina frente al volátil escenario internacional de la postpandemia y la competencia entre

China y los Estados Unidos: ¿aquiescencia, pragmatismo o autonomía? DOI: https://doi.org/10.24215/24689912e035

grande de su historia por US $\$ 56,3$ mil millones, que concentró el $60 \%$ de su cartera ${ }^{19}$. Muchos analistas interpretaron este hecho como un apoyo político directo de Donald Trump a la estabilidad económica de la Argentina para otorgarle el plafón necesario al gobierno para que consiga su reelección (Cantamutto y Féliz, 2021). Este nuevo ciclo de endeudamiento externo con el préstamo pedido al FMI condicionaría la política económica doméstica y dejaría a la Argentina al borde de un nuevo default.

En los primeros meses de gobierno primó la idea de que un acercamiento a los Estados Unidos exigía un compromiso más marcado en términos de un alejamiento de China, no tanto en temas comerciales sino sobre todo en aspectos estratégicos. La relación con China se construyó, bajo esta lógica, como oposición a la que había mantenido el gobierno anterior, caracterizada ahora como una aproximación "ideológica" (Paikin, 2018). Debido a esto, durante el primer año de gobierno se rejerarquizaron las relaciones internacionales y tanto China como Rusia quedaron relegados a un segundo plano (Simonoff, 2017).

Sin embargo, luego del recelo inicial el gobierno argentino pasó rápidamente de una postura crítica $^{20}$ a una pragmática en el manejo de la relación bilateral con China (Pascual y Ghiotto, 2019). La influencia de China para el comercio exterior argentino y la presión de una porción no menor de la base política de Cambiemos (el sector agroindustrial - exportador), hicieron que el gobierno modifique su postura inicial de recelo y busque abiertamente la normalización de las relaciones con el país asiático, lo que se reflejó en varias visitas oficiales y en acuerdos bilaterales.

Debe haber pocos países en el mundo más complementarios que la Argentina y China. Los argentinos tenemos mucho para aportarle en los temas de seguridad alimentaria, en temas que tengan vinculación con el desarrollo de tecnología, en lo que tiene que ver con el deporte (...). Y este país tiene mucho para aportarnos también en el tema tecnología, pero sobre todo en la construcción de infraestructura.

\footnotetext{
${ }^{19}$ La actuación del FMI como "prestamista de última instancia" ha sido denunciada por intelectuales, académicos y organizaciones de derechos humanos. Lejos de garantizar el desarrollo sostenible, el dinero prestado ha financiado la fuga de capitales y la especulación financiera, desfinanciando al Estado, condicionando su accionar y comprometiendo la garantía de derechos económicos, sociales, culturales y ambientales (Bohoslavsky \& Cantamutto, 2021).

${ }^{20}$ Durante el primer año de gobierno se inició la revisión de la Asociación Estratégica Integral (AEI) y numerosos contratos firmados por la administración anterior y se rechazó el acuerdo para la construcción de las represas Jorge Cepernik y Néstor Kirchner en la Provincia de Santa Cruz, que se habían adjudicado a un consorcio conformado por la empresa china Gezhouba Group Company y la argentina Electroingeniería S.A. Luego de esta medida, China dejó de comprar aceite de soja a la Argentina y obligó al gobierno a recular y a normalizar las relaciones bilaterales.
} 
La Argentina tiene un enorme desafío siendo un país tan grande para la conectividad, justo lo que hablamos durante las últimas 48 horas que tuve la suerte de ser invitado en la Convocatoria Una Franja, Una Ruta. Sudamérica en general y la Argentina en particular tienen una labor por delante enorme en la construcción de rutas, puentes, energía, puertos, aeropuertos que nos vinculen dentro del país y con el resto de la región. (Macri, 2017a, párr. 1)

China es actualmente el segundo socio comercial de importancia para la Argentina y uno de los principales demandantes de porotos de soja argentinos, concentrando más del $80 \%$ de las ventas externas de este producto. También ocupa un lugar central en materia de inversiones (principalmente en energía e infraestructura) y en materia financiera debido a los acuerdos firmados entre el Banco Central de la República Argentina y el Banco Popular de China. Tanto el gobierno como los bancos chinos han otorgado miles de millones de dólares en préstamos para inversiones sociales e infraestructura y firmas chinas han absorbido una gran cantidad de empresas privadas, radicándose principalmente en los sectores de energía y transporte (Donaubauer, J., López, A., y Ramos, D., 2017).

A pesar de su promesa de campaña, rápidamente quedó de manifiesto que la política exterior de la alianza Cambiemos estuvo teñida de un barniz fuertemente ideológico, globalista y neoliberal. Pese a esto, tuvo que adaptar sus posicionamientos discursivos y sus prácticas en materia de política exterior a una postura más pragmática debido a los resultados de las elecciones en los Estados Unidos, al crecimiento de China en los foros internacionales y a la presión interna de sus bases políticas y del poder económico. La apuesta por la apertura fracasó tanto en su objetivo de atraer inversiones como en el de fortalecer las relaciones comerciales internacionales y colisionó con un cambio en el contexto internacional signado por medidas proteccionistas y la guerra comercial entre Estados Unidos y China. La apuesta por el multilateralismo también encontró un límite en la pérdida de prioridad de los espacios multilaterales para las principales potencias del mundo, principalmente Estados Unidos.

Macri asumió con la idea de "volver al mundo" pero el mundo al que se refería, como vimos previamente, había sufrido enormes transformaciones. La priorización de una integración a partir de una mirada aperturista, su apuesta por el multilateralismo y por el libre comercio en un contexto de crisis de la globalización, del multilateralismo y disputa entre las dos grandes potencias, así como el alineamiento automático a la política exterior de los Estados Unidos y 
La política exterior argentina frente al volátil escenario internacional de la postpandemia y la competencia entre China y los Estados Unidos: ¿aquiescencia, pragmatismo o autonomía? DOI: https://doi.org/10.24215/24689912e035

la contracción de una nueva deuda con el FMI pusieron rápidamente en evidencia las debilidades del enfoque que orientó su política exterior.

\section{El pragmatismo de la Política Exterior del “Frente de todos” en UN CONTEXTO CRÍTICO}

En el discurso inaugural de las sesiones parlamentarias en marzo de 2020 Alberto Fernández delineó algunos de los ejes de su política exterior. Allí destacó el apoyo al multilateralismo y a la solución pacífica de las controversias, el fortalecimiento de la integración regional en el Mercosur y, a nivel global, la apertura del diálogo con potencias de América y Europa y el logro de asociaciones estratégicas integrales con China y con Rusia, entre otros puntos (Fernández, 2020).

La lógica de los lineamientos de su política exterior intentaría buscar, tímidamente, una mayor autonomía mediante un fortalecimiento de los vínculos Sur-Sur, una diversificación de las asociaciones bilaterales y un abandono del alineamiento acrítico con respecto a los intereses hemisféricos de los Estados Unidos. La visión general, sin embargo, apuntaría a sostener una política exterior principalmente pragmática:

Construimos relaciones serias con las grandes potencias y los grandes bloques, como los Estados Unidos, China, Rusia, Medio Oriente y la Unión Europea. Dejamos atrás la política de sumisión y fotos. Consolidamos un idealismo realista y un pragmatismo que no olvida los valores. Buscamos resultados que se noten en la vida cotidiana. (Fernández, 2021, parr. 305).

Con la irrupción de la pandemia por el COVID-19, sin embargo, la agenda externa se vería completamente trastocada y todos los esfuerzos pasarían a concentrarse en la atención sanitaria. Para ello se establecieron acuerdos de cooperación sanitaria con China, se tomaron iniciativas en el Mercosur ${ }^{21}$ y se firmaron contratos de abastecimiento de vacunas con los principales laboratorios del mundo y también acuerdos de transferencia tecnológica con los principales laboratorios (Gamelaya (Sputnik), BioCubaFarma (Soberana y Abdala), Corporación Grupo Farmacéutico Nacional Chino (Sinopharm) y Oxford (AstraZeneca) para producir dosis en plantas locales.

${ }^{21}$ Como señalan Malacalza y Hirst (2020), el Mercosur activó las redes de interacción sanitaria, educativa y en derechos humanos. El gobierno argentino propuso financiar el Fondo de Convergencia Estructural (FOCEM) para un proyecto de colaboración científica en biomedicina y testeo del virus. 
La política exterior argentina frente al volátil escenario internacional de la postpandemia y la competencia entre China y los Estados Unidos: ¿aquiescencia, pragmatismo o autonomía? DOI: https://doi.org/10.24215/24689912e035

Hasta la irrupción de la pandemia, la renegociación de la deuda externa había sido el tema central en la agenda. En la administración de Fernández, como lo fue en la de Kirchner, el desendeudamiento se busca como objetivo estratégico prioritario ya que la deuda externa se vincula a la falta de soberanía nacional (Coscarelli, 2020). En este marco es que Alberto Fernández tuvo que buscar apoyo de los Estados Unidos y los países de la Unión Europea para la negociación con los acreedores privados ${ }^{22}$, el Club de París y el $\mathrm{FMl}^{23}$. Como una muestra de esta necesidad intentó proyectar una imagen de cercanía a Washington realizando su primer viaje al exterior como presidente a Israel. También proyectó una imagen de moderación, equilibrio y pragmatismo eligiendo a Felipe Solá como ministro de Relaciones Exteriores y a Jorge Arguello como Embajador en Washington ${ }^{24}$.

En paralelo a esto, sin embargo, intentó articular en América Latina un incipiente eje progresista y reconstruir cierta institucionalidad regional en la búsqueda de grados mayores de autonomía, marcando un claro eje programático: "Nuestro presente y nuestro futuro es con la Patria Grande. Queremos una América Latina unida" (Fernández, 2021, párr. 301). En esta búsqueda envió al ministro de Relaciones Exteriores Felipe Solá a la Cumbre de la CELAC en México en enero de 2020 y realizó un acercamiento al Grupo de Puebla comandado por los líderes de centro-izquierda José Manuel López Obrador (México) y Marco Enríquez-Ominami (Chile) $)^{25}$. Además de estos movimientos ofreció asilo a Evo Morales frente al golpe de estado de Jeanine Añez en Bolivia en 2019 y estableció una

22 El ministro de Economía Martín Guzmán logró en el mes de agosto de 2020 la aceptación del 93\% de los bonistas (que concentran el $99 \%$ de la deuda total) de la propuesta argentina de reestructurar los compromisos financieros internacionales.

${ }^{23} \mathrm{Al}$ momento del envío de este trabajo ya se había logrado un acuerdo con los acreedores privados y todavía se estaban negociando los términos del acuerdo para refinanciar la deuda con el Fondo Monetario Internacional. Algunos analistas han señalado las diferencias entre la postura histórica de los Estados Unidos, que solía exigir reformas del Estado y programas de Ajuste Estructural, y la postura actual, en donde se percibe que las demandas podrían vincularse a asumir mayores compromisos estratégicos en el marco de la disputa con China. La transición política entre Trump y Biden podría llegar a modificar esta situación, aunque se perciben muchas líneas de continuidad en la política exterior de ambas administraciones (Campanella, 2020).

${ }^{24}$ Arguello ya había sido Embajador ante la ONU entre 2007 y 2011 y ante Estados Unidos entre 2011 y 2013. En aquel momento, el principal objetivo era la negociación contra los "fondos buitres" (Coscarelli, 2020)

${ }^{25}$ El Grupo de Puebla nació en 2019 en México como un espacio de contraposición al viraje conservador de los países de la región, cuestionando la hegemonía del Grupo de Lima y PROSUR y recuperando el proyecto de la UNASUR. En la declaración conjunta a la que llegaron los líderes en la cumbre de noviembre de 2020 se incluyeron claros posicionamientos en lo que respecta a la lucha a favor de la igualdad social, la igualdad de género, la sustentabilidad ambiental y la profundización de la democracia (Miguez, 2020). 
La política exterior argentina frente al volátil escenario internacional de la postpandemia y la competencia entre

China y los Estados Unidos: ¿aquiescencia, pragmatismo o autonomía? DOI: https://doi.org/10.24215/24689912e035

postura equidistante con respecto a la situación de Venezuela ${ }^{26}$, lo que implicó un notable cambio de posicionamiento con respecto a la anterior administración. Finalmente, definió la salida de la Argentina del Grupo de Lima en el mes de marzo de 2021 y se pronunció a favor de la reconstitución de la UNASUR ${ }^{27}$, aunque todavía no se hayan registrado avances concretos en esta dirección.

Con respecto al bloque regional, la prioridad ha sido, al menos desde el punto de vista discursivo, el fortalecimiento del Mercosur. Se han propuesto tres objetivos concretos con respecto al bloque regional: neutralizar el intento flexibilizador, sumar a Bolivia como miembro permanente y lograr el consenso sobre la relación del bloque con el resto del mundo (Taglioni, 2021). El Canciller Felipe Solá se ha encargado de dejar en claro que el Mercosur "fue y sigue siendo el proyecto político regional más importante de la Argentina. Es una política de Estado que debe ser sostenida por encima de los cambios de gobierno" (Solá, 2020, párr. 1). El objetivo apuntó a utilizar la solidez del bloque para ganar competitividad, proyección y capacidad negociadora a nivel internacional. En otras palabras, "la Argentina se integra al mundo con la frente en alto y no de rodillas" (Solá, 2021, párr. 1). El principal obstáculo en la reconstrucción de la institucionalidad regional y la búsqueda de una mayor autonomía es, sin lugar a dudas, la difícil relación bilateral con Brasil debido a las desavenencias con el presidente Jair Bolsonaro.

En abril de 2020 Brasil, Paraguay y Uruguay intentaron acelerar la firma de un tratado de libre comercio con Corea del Sur, lo que generó un fuerte conflicto diplomático con la Argentina $^{28}$, que intentó evitar que cada país firme individualmente y a la vez obstaculizar el

26 La pretendida equidistancia, sin embargo, le ha generado a Alberto Fernández muchos inconvenientes y cierta incomodidad a la hora de referirse sobre el tema. En declaraciones a los medios ha llegado a admitir que "Poco a poco el problema de derechos humanos en Venezuela fue desapareciendo", una afirmación que le ha hecho recibir muchas críticas tanto por reconocer que había un problema de derechos humanos como por afirmar que fue desapareciendo (La Nación, 2021a). Antes de estos dichos, Fernández había firmado el conocido "Documento Bachelet" que la ONU redactó sobre la situación de los derechos humanos en Venezuela (La Nación, 2019), aunque luego retirara su apoyo a la demanda contra Nicolás Maduro que tramita en la Corte Penal Internacional (CPI) en La Haya (La Nación, 2021b).

27 Para más información véase: https://www.pagina12.com.ar/300680-alberto-fernandez-llamo-areconstruir-la-unasur-es-lo-que-ma

${ }^{28}$ La Argentina había anunciado que saldría de la mesa de negociación de acuerdos de libre comercio del bloque y que daría libertad para que el resto de los países avance en las negociaciones en curso. Sin embargo, después de una semana de mucha tensión, la Cancillería anunció con un breve comunicado que la Argentina seguiría participando de la "búsqueda de soluciones conjuntas" para poder "avanzar a ritmos diferenciados en la agenda de relacionamiento externo" del bloque, 
La política exterior argentina frente al volátil escenario internacional de la postpandemia y la competencia entre China y los Estados Unidos: ¿aquiescencia, pragmatismo o autonomía? DOI: https://doi.org/10.24215/24689912e035

avance de la firma como bloque. Sin retirarse de los acuerdos en negociación, la posición argentina logró frenar la firma del tratado argumentando que debía avanzarse sobre la base de estudios de impacto actualizados. Sin embargo, lejos de zanjar la discusión sobre la flexibilización, esta se volvió a presentar en 2021 en la reunión por la conmemoración de los 30 años del bloque, donde Uruguay y Brasil $^{29}$ volvieron a insistir en que los países miembros puedan negociar tratados de libre comercio con países externos al bloque de manera bilateral y buscaron negociar además una rebaja del Arancel Externo Común (AEC) (GENCI, 2021)

El acuerdo de libre comercio con la Unión Europea ha quedado nuevamente en el centro de la discusión ya que ha sido denunciado por algunos países como Austria, Francia, Bélgica y los Países Bajos. El principal obstáculo es el desacuerdo hacia la política ambiental sostenida por Brasil ${ }^{30}$, pero también existe una fuerte resistencia del sector agropecuario europeo que teme perder sus privilegios. La Argentina, hasta el momento, aboga por avanzar con acuerdos complementarios vinculados al cambio climático, el cuidado del medio ambiente y la deforestación mientras continúa la negociación del tratado comercial, que Fernández es partidario de ratificar (GENCI, 2021).

Fernández ha apostado desde el día uno por la construcción de un "multilateralismo solidario y pragmático" (Berro, 2021). La relevancia de la OMS en la gestión de la pandemia, la creciente gravitación de la $\mathrm{OMC}^{31}$ y el triunfo de Biden ${ }^{32}$ en los EE.UU., que permiten proyectar cierta restauración del funcionamiento de las instituciones multilaterales, han dado cierto plafón internacional a esta estrategia. En el ámbito multilateral se siguió impulsando la Cuestión Malvinas y se volcó la estrategia de la adquisición de vacunas para

manteniendo la idea del Mercosur como un bloque homogéneo (Ministerio de Relaciones Exteriores, Comercio Internacional y Culto Argentina, 2020c, párr. 1).

${ }^{29}$ A la influencia histórica de los Estados Unidos se ha sumado en los últimos veinte años la presencia creciente de China, que ha empoderado a sectores vinculados a los agronegocios. Esta mutación está en la base de las razones que explican la actual postura de Brasil con respecto a la integración regional en el Mercosur y la búsqueda de su flexibilización.

30 En un reciente estudio de la London School of Economics se realizó un impacto de sustentabilidad económica, social, ambiental y de derechos humanos del Tratado y se concluyó que tendría un impacto positivo en la economía de ambos bloques, pero planteó preocupaciones con respecto al impacto sobre el medio ambiente, los derechos humanos y las poblaciones indígenas (LSE, 2020)

${ }^{31}$ La discusión sobre Patentes, la elección de Ngozi Okonjo-Iweala como directora general, la proximidad de la $12^{\circ}$ Conferencia Ministerial y el cambio de gobierno en los Estados Unidos han revitalizado el organismo, aunque todavía persiste el bloqueo del Órgano de Apelaciones y las diferencias entre los países miembro con respecto a temas sensibles (GENCI, 2021).

${ }^{32}$ El triunfo de Biden podría mejorar la convergencia bilateral en algunos temas de la agenda global multilateral sin exigir mayores compromisos de soberanía. 
La política exterior argentina frente al volátil escenario internacional de la postpandemia y la competencia entre China y los Estados Unidos: ¿aquiescencia, pragmatismo o autonomía? DOI: https://doi.org/10.24215/24689912e035

la pandemia. El estado crítico de los organismos multilaterales, sin embargo, difícilmente se revierta. La disputa entre Estados Unidos y China seguirá tiñendo las discusiones en estos foros y el devenir de la política exterior Argentina.

El contexto internacional y regional atentan por el momento contra la promoción de un nuevo proyecto de integración. A diferencia de la época de la marea rosa, en la actualidad existen en Brasil, Uruguay, Paraguay y Chile gobiernos de signo político contrario a las ideas integracionistas. El contexto internacional de plena disputa entre Estados Unidos y China agrava la situación ya que exige crecientes compromisos geopolíticos y la Argentina se encuentra en una posición muy frágil y con una doble dependencia.

La relación con los Estados Unidos seguirá siendo asimétrica y presentando una marcada dependencia en lo que respecta a la política de defensa y seguridad y a mecanismos financieros como los del endeudamiento externo, que han oficiado como correas de transmisión de programas de ajuste fiscal, privatizaciones y reforma del Estado. Con respecto a China resulta evidente la necesidad seguir buscando acuerdos de complementariedad dada su relevancia indiscutible en el escenario mundial. Sin embargo, la relación ha distado mucho de seguir una lógica de cooperación Sur-Sur que permita una estrategia de industrialización según necesidades locales y regionales y un financiamiento del desarrollo. Lejos de eso, la lógica predominante ha tendido a reproducir relaciones del tipo centro-periferia, con una presión creciente sobre la explotación de recursos naturales que pone en riesgo la soberanía. Este esquema ha generado, a la par de la reprimarización de las exportaciones, una fuerte vulnerabilidad frente a la volatilidad de los precios internacionales de las commodities.

En la lectura de la situación de la región frente a la disputa entre los Estados Unidos y China, la declaración conjunta del Grupo de Puebla en la cumbre de noviembre de 2020 planteó con claridad la propuesta un "no alineamiento activo" como estrategia política internacional y de "fortalecer alianzas con el mundo multipolar que afiance el multilateralismo" en su lugar ${ }^{33}$. Para la Argentina la relación con los EEUU es prioritaria de cara a la negociación con el FMI ya que es el principal acreedor y el actor más influyente del Organismo. Además, tras la fuerte asociación entre Trump y Bolsonaro, Joe Biden podría buscar un aliado político más moderado en la región y la Argentina podría cumplir ese

${ }^{33}$ Para más información, véase: https://www.perfil.com/noticias/politica/manifiesto-grupo-puebla-dijosomo-parte-de-la-larga-marcha-de-nuestra-america-latina-por-liberacion.phtml 
La política exterior argentina frente al volátil escenario internacional de la postpandemia y la competencia entre China y los Estados Unidos: ¿aquiescencia, pragmatismo o autonomía? DOI: https://doi.org/10.24215/24689912e035

papel. El vínculo con China aparece también como estratégico y representará un desafío político para el gobierno encontrar una posición pragmática y equidistante. China es el segundo socio comercial más importante y uno de los principales proveedores de vacunas, así como también de potenciales inversiones en la industria ${ }^{34}$, en infraestructura ${ }^{35}$ y de recursos financieros. Si bien hasta el momento ha mantenido una postura moderada y pretendidamente equidistante, quizás en algún momento deba enfrentar un compromiso más explícito con alguna de las dos partes ${ }^{36}$.

\section{VIII. ¿QUÉ TIPO DE POLÍTICA EXTERIOR PARA EL NUEVO ESCENARIO INTERNACIONAL? Comentarios Finales}

La Pandemia agudizó las desigualdades propias de la economía neoliberal y dejó en evidencia la necesidad de contar con sistemas nacionales que garanticen el acceso a bienes y servicios esenciales. Si bien es difícil que la termine con el ciclo neoliberal y con la hegemonía norteamericana, la discusión apunta a identificar si pone de manifiesto la crisis de este ciclo y si permite pensar en una aceleración de las tendencias que se venían observando que hacia un nuevo orden (Traverso, 2020).

La crisis de los sistemas de salud y la fragilidad de muchos Estados para garantizar condiciones mínimas de bienestar para su población han quedado en evidencia. Quizás uno de los principales efectos de la situación actual sea, como señala Touzon (2020), un cambio de las mentalidades alrededor del mundo que nos permita una confrontación frontal con los límites del modelo social, económico y político del capitalismo en su fase neoliberal. A pesar de estas tendencias cabe preguntarse, como lo hacen Rodríguez y Touzon (2020), si es

\footnotetext{
34 Uno de los principales reveses del gobierno argentino fue la firma del "Acuerdo Porcino" con la República Popular China para la instalación de granjas industriales de cerdos con destino al país asiático (Cancillería, 2020b). El acuerdo fue fuertemente resistido por algunas organizaciones ambientalistas y sectores de la población que argumentaron que generaría una mayor presión a la deforestación (Greenpeace, 2020). Debido a esto debió ponerse en suspenso y hasta el momento no ha sido reactivado.

35 Hacia fines de 2020 se firmaron cuatro acuerdos entre Argentina y China por un total de US $\$ 4.695$ millones para reactivar líneas ferroviarias y adquirir material rodante para el transporte ferroviario de pasajeros (Cancillería, 2020a)

${ }^{36} \mathrm{Xi}$ Jinping le ha cursado una invitación oficial al presidente argentino para que visite Beijing con el objetivo de rubricar el ingreso de la Argentina a la Nueva Ruta de la Seda y al Banco Asiático de Inversiones en Infraestructura. Si bien se proyectaba para el mes de mayo de 2021, a la fecha de entrega de este trabajo todavía no se había concretado debido al empeoramiento de la situación epidemiológica en la Argentina.
} 
La política exterior argentina frente al volátil escenario internacional de la postpandemia y la competencia entre

"cerrable" la globalización o si, en su lugar, nos estamos dirigiendo a una "globalización con geometría variable", como ha manifestado García Linera (2020).

Si buscan garantizar el acceso a derechos humanos elementales a sus ciudadanos, los Estados tendrán que asumir un rol más activo para conquistar crecientes espacios de soberanía energética, alimentaria, sanitaria, de telecomunicaciones, industrial y financiera. Las transformaciones deben apuntar al fortalecimiento de los mercados locales y a la creación de cadenas de provisión y abastecimiento nacionales o regionales. Esto no implica necesariamente que lo mejor sea revertir por completo la globalización, pero sí que, como recomienda García Linera (2020), se desarrolle un "régimen económico anfibio" que proteja ciertos espacios y aproveche la articulación de las cadenas globales en otros. Es evidente que para lograr esto existen precondiciones como el fortalecimiento de alianzas estratégicas y la implementación de profundas reformas fiscales.

En el marco de estas transformaciones, cabe preguntarse cuál es la política exterior más apropiada para la Argentina en este contexto. ¿Adoptar una lógica de aquiescencia y alinearse a China o a Estados Unidos o mantenerse no alineados buscando la autonomía mediante el fortalecimiento de la integración regional y las relaciones Sur-Sur? ¿Promover nuevos acuerdos de libre comercio o proteger algunos espacios regionales de la competencia despiadada del mercado internacional? ¿Continuar buscando soluciones en los ámbitos multilaterales o apostar por acuerdos bilaterales?

En términos estrictamente económicos, difícilmente experimentemos en los próximos años una ventana de oportunidades para la región en general y la Argentina en particular de ganar peso en el escenario internacional (Malamud, 2019). La vinculación con nuestros principales socios comerciales por fuera de la región continúa siendo dependiente de las exportaciones de minerales, combustibles y materias primas y de la afluencia de capitales externos. La volatilidad de los bajos precios de las commodities y las altas tasas de interés internacionales hacen depender la economía de factores externos que la vuelven más vulnerable y restan todavía más los márgenes de maniobra para buscar la autonomía. Además de esto, se espera que continúen las medidas proteccionistas en los principales mercados y se realicen menores flujos de capitales hacia la región (Marchini, 2020).

El ascenso de China construye un contrapeso a la hegemonía norteamericana y representa una amenaza a su influencia en la región. Los Estados Unidos han estado reinterpretando la famosa Doctrina Monroe de "América para los americanos". Sin embargo, a diferencia del 
La política exterior argentina frente al volátil escenario internacional de la postpandemia y la competencia entre

pasado, han perdido capacidad de liderazgo y se han concentrado en una política de fortalecimiento doméstico más que en la provisión de bienes públicos globales. En el marco de la disputa entre Estados Unidos y China es altamente probable que de aquí a unos años se vaya solidificando la "doble dependencia" y que ambas potencias exijan posicionamientos más definidos que pueden reducir aún más los márgenes de acción. La política exterior argentina estará, por lo tanto, signada por esta disputa en el escenario geopolítico global y debería evitar mayores compromisos y buscar, como lo expresa el documento del Grupo de Puebla, un "no alineamiento activo".

El temor por el crecimiento de la influencia china puede llegar a generar condiciones similares a las de la posguerra cuando Occidente debió ofrecer y permitir el desarrollo de herramientas que mejoraran el bienestar interno de los países del entonces llamado "Tercer Mundo". Durante la guerra fría, en pleno bipolarismo, los países del Sur Global experimentaron un breve interregno en los que lograron aprovechar parcialmente ese margen de maniobra abierto por la confrontación entre las dos potencias ${ }^{37}$. Quizás el actual sea un escenario en donde se deba aspirar, al menos como horizonte, a una articulación política similar. Un acercamiento mayor a la lógica de la autonomía sin llegar a la confrontación con ambas potencias, en este contexto, parece ser la más adecuada.

Una precondición para lograr un mejor posicionamiento internacional es, por lo tanto, el fortalecimiento de los procesos de integración regional. La falta de liderazgos regionales y la fragmentación actual atentan contra la necesaria unidad ${ }^{38}$. Como señala Tokatlian (2019), "en la medida en que sigamos fragmentados, con problemas de coordinación, y haciendo trizas nuestros procesos de integración, nuestra capacidad negociadora hacia ambos va a disminuir". Argentina debe seguir apostando por el multilateralismo pero debe también buscar una posición equidistante ante el conflicto por el liderazgo mundial. Uno de los prerequisitos es mejorar la capacidad negociadora, para lo que resulta necesario el fortalecimiento del bloque regional.

37 Como señala Febbro (2020), "ese conflicto fue una de las condiciones para las victorias de los movimientos de liberación en Vietnam, Cuba, Mozambique, Angola, Guinea (...) y de allí nació el Movimiento de Países No Alineados (...) y la Conferencia de las Naciones Unidas sobre Comercio y Desarrollo (UNCTAD)".

38 Brasil pudo convertirse en líder indiscutido de la región con la fuerte expansión interna e internacional que experimentó entre 2002 y 2013 en pleno contexto de multipolarismo y crecimiento de los BRICS. Sin embargo, las diferencias entre países alejaron más todavía los consensos necesarios para fortalecer los mecanismos regionales. 
La política exterior argentina frente al volátil escenario internacional de la postpandemia y la competencia entre

Además de la fragmentación, en este momento las instituciones creadas para el fortalecimiento de la integración regional se encuentran en crisis. La Comunidad de Estados Latinoamericanos y Caribeños (CELAC) y la Unión de Naciones Suramericanas (UNASUR) han sido vaciadas y el Mercosur se encuentra partido, con gobiernos de distinto signo político que le imprimen direcciones divergentes ${ }^{39}$. La crisis del Mercosur es muy profunda y no se agota en las diferencias sobre la "agenda extrarregional" para firmar acuerdos de libre comercio con terceros países. Lo que está en jaque es el mismo proyecto de integración "como espacio amplio de cooperación, confianza y de identidad compartida" (Frenkel, 2020).

En el contexto de volatilidad y en plena transición hacia un nuevo escenario internacional es prioritario fortalecer la integración regional y conquistar mayores espacios de autonomía para que los Estados puedan garantizar la soberanía económica y la justicia social y conseguir mayor poder de negociación en los acuerdos internacionales. Es necesario reconstruir las instituciones regionales y lograr una nueva articulación política con el resto de los líderes de la región para darle forma una voz unificada frente a otros interlocutores.

En este contexto crítico es donde debe resurgir con más fuerza el proyecto integracionista de América Latina porque pueden desarrollarse ventajas geoestratégicas si se conquistan esos espacios de autonomía. Existen oportunidades que pueden habilitar márgenes para reconstruir capacidades estatales y herramientas de desarrollo y bienestar social en sectores estratégicos como energía, infraestructura, agricultura, y algunos sectores industriales. Para lograrlo se debe lograr una posición consensuada con respecto a algunos temas en común y se deben impulsar nuevamente proyectos que permitan una mayor integración productiva regional y la reducción de asimetrías estructurales ${ }^{40}$. Además de esto se debe aprovechar el potencial del Cono Sur para agregar valor regional y promover una mayor integración de cadenas productivas entre los países del Mercosur con Chile y Bolivia.

Todo indica que el contexto internacional exige estrategias de política exterior pragmáticas, pero más cercanas a la lógica autonomista, pero los proyectos de integración en América

39 El extremo de esta divergencia ha llevado a que por primera vez en mucho tiempo para las Fuerzas Armadas Brasileñas exista una hipótesis de conflicto con Argentina debido a la instalación de una base militar china (Frenkel, 2020)

40 En el Mercosur las asimetrías entre los socios nunca fueron abordadas de modo sistemático y explican en gran parte las tensiones existentes al interior del bloque y las razones que llevan cíclicamente a Paraguay y a Uruguay a buscar flexibilizarlo. 
La política exterior argentina frente al volátil escenario internacional de la postpandemia y la competencia entre

Latina se encuentran en uno de los mayores momentos de fragmentación en mucho tiempo. Cuando pase la pandemia, con mucho de construcción política y una cuota de suerte en los avatares de las coincidencias históricas de los liderazgos regionales quizás se presente el momento de buscar una nueva reconstrucción de las instituciones regionales, aunque deberán construirse acuerdos políticos para que sea un proyecto de largo plazo.

\section{REFERENCIAS BIBLIOGRÁFICAS}

Actis, E. y Creus, N. (2020, junio). Un mundo acelerado: ¿bipolaridad o nueva guerra fría? Revista Nueva Sociedad Opinión. https://nuso.org/articulo/China-Estados-Unidos-Guerrafria/

Allison, G. (2017). Destined for War. Can America and China escape Thucydides's Trap? New York: Houghton Mifflin Harcourt.

Arceo, E. (2018). China ¿el nuevo poder hegemónico? Realidad económica, 47(319), 9-40. http://www.iade.org.ar/system/files/ediciones/re-319.pdf

Berro, J. (202, 6 de febrero). Multilateralismo solidario y pragmático, los ejes de la agenda internacional del Gobierno. Télam. https:/www.telam.com.ar/notas/202102/543811gobierno-poltica-exterior-multilateralismo-alberto-fernandez.html

Bloomberg. (2021, 17 de mayo). China Steps Up Efforts to Join Trade Pact Created to Exclude It. https://www.bloomberg.com/news/articles/2021-05-17/china-steps-up-efforts-tojoin-trade-pact-created-to-exclude-it

Bohoslavsky, J. P. y Cantamutto, F. (2021). FMI, neoliberalismo y derechos humanos. Derechos En Acción, 18(18), e478. https://doi.org/10.24215/25251678e478

Bremmer, I. y Kupchan, C. (2020). Risk 2: The Great Decoupling. Top Risks 2020 Coronavirus Edition, Eurasia Group Report. https://www.eurasiagroup.net/live-post/risk-2great-decoupling

Busso, A. (2019). Argentina nuevamente en crisis: reflexiones sobre las limitaciones de una política de alineamiento con Estados Unidos". Anuario en Relaciones Internacionales del IRI, 2019, 1-10. http://sedici.unlp.edu.ar/handle/10915/95943

Cafferata, M. (2020, 20 de enero). Política exterior del Gobierno: pragmatismo en un contexto mundial convulsionado. Página/12. https://www.pagina12.com.ar/242662-politicaexterior-del-gobierno-pragmatismo-en-un-contexto-mu

Campanella, E. (2020, 5 de noviembre). Free Trade is Over. Foreign Policy. https://foreignpolicy.com/2020/11/05/protectionism-trump-biden-buy-american-tariffs/

Cantamutto, F. y Féliz, M. (2021). Argentina entre la sostenibilidad de la deuda y la vida. Revista Nuestramérica, 9(17). http://revistanuestramerica.cl/ojs/index.php/nuestramerica/article/view/301 
Carreiras, H. y Malamud, A. (2020, 10 de mayo). Geopolítica del coronavirus. El Economista. https://eleconomista.com.ar/2020-05-geopolitica-del-coronavirus/

Coscarelli, S. Y. (2020). La política exterior de Alberto Fernández y los Estados Unidos. [Trabajo Final para la materia Política Exterior Argentina, dictada por el Dr. Alejandro Simonoff, en la Maestría en Relaciones Internacionales] UNLP JURSOC IRI. http://sedici.unlp.edu.ar/handle/10915/109755

Diamand, M. (1985). El péndulo argentino: ¿hasta cuándo? Cuadernos del Centro de Estudios de la Realidad Económica, 1(1).

Donaubauer, J., López, A., y Ramos, D. (2017). FDI and trade: is China relevant for the future of our environment? The case of Argentina. En R. Ray, K. Gallagher, A. López y C. Sanborn (Eds.), China and Sustainable Development in Latin America: The Social and Environmental Dimension, (33-72). https://www.jstor.org/stable/j.ctt1jktqpm

Febbro, E. (2020, 10 de mayo). El mundo después del coronavirus: el impulso es hacia un sistema postcapitalista. Página/12. https://www.pagina12.com.ar/264898-el-mundodespues-del-coronavirus-el-impulso-es-hacia-un-sist

Fernández, A. (2020, 1 de marzo). Discurso del presidente de la Nación, Alberto Fernández, en la apertura del $138^{\circ}$ periodo de sesiones ordinarias del Congreso de la Nación. Presidencia de la Nación Argentina. https://www.casarosada.gob.ar/informacion/discursos/46746-discurso-del-presidentealberto-fernandez-al-encabezar-la-apertura-del-periodo-138-de-sesiones-ordinarias-delcongreso-de-la-nacion

Fernández, A. (2021, 1 de marzo 2021). Palabras del Presidente Alberto Fernández en la Apertura del 139 período de sesiones ordinarias, del Honorable Congreso de la Nación Argentina. Presidencia de la Nación Argentina. https://www.casarosada.gob.ar/informacion/discursos/47566-palabras-del-presidentealberto-fernandez-en-la-apertura-del-139-periodo-de-sesiones-ordinarias-del-honorablecongreso-de-la-nacion-argentina-caba

Fiori, J. L. (2020, 10 de abril). Prognóstico é ruim e vai piorar. Tutameia, https://tutameia.jor.br/prognostico-e-ruim-e-vai-piorar-diz-fiori/

Frenkel, A. y Azzi, D. (2018). Cambio y ajuste: la política exterior de Argentina y Brasil en un mundo en transición (2015-2017). Colombia Internacional, (96), 177-207, https://doi.org/10.7440/colombiaint96.2018.07

Frenkel, A. (2020, 12 de mayo). Mercosur y Coronavirus: una comunidad de seguridad en riesgo. Diario Perfil. https://www.perfil.com/noticias/internacional/mercosur-coronaviruscomunidad-de-seguridad-en-riesgo.phtml

Fusaro, L. (2017). Why China is Different: Hegemony, Revolutions and the Rise of Contender States. Return of Marxian Macro-dynamics in East Asia, 32, 185-223. https://doi.org/10.1108/S0161-723020170000032011 
La política exterior argentina frente al volátil escenario internacional de la postpandemia y la competencia entre China y los Estados Unidos: ¿aquiescencia, pragmatismo o autonomía? DOI: https://doi.org/10.24215/24689912e035

García Linera, A. (2020 junio). El fin del porvenir como repetición / Entrevistadopor Ayelén Oliva. Una agenda progresista para salir de la crisis, Le Monde Diplomatique Edición Conosur. https://www. eldiplo.org/notas-web/el-fin-del-porvenir-como-repeticion/

Grupo de Estudio sobre Negociaciones Comerciales Internacionales (2021). El Estado de las Negociaciones Comerciales Internacionales. Informe 1/2021. http://hdl.handle.net/2133/20826.

Ghiotto, L. y Echaide, J, (2020). El Acuerdo entre el Mercosur y la Unión Europea. Estudio integral de sus cláusulas y efectos. The Greens/EFA, Fundación Rosa Luxemburgo y CLACSO. https://www.clacso.org/acuerdo-entre-el-mercosur-y-la-union-europea/

Graf Rey, M. (2020, 27 de mayo). La Política Exterior Argentina en tiempos de pandemia. Observatorio de Política Exterior Argentina. https://www.opeargentina.org/post/lapol\%C3\%ADtica-exterior-argentina-en-tiempos-de-pandemia

Greenpace. (2020, 11 de agosto). Greenpeace advierte que el acuerdo con China para producir chanchos generará más deforestación. https://www.greenpeace.org/argentina/story/issues/bosques/greenpeace-advierte-que-elacuerdo-con-china-para-producir-chanchos-generara-mas-deforestacion/

Grigera, J. (2020). Sal en la herida: la crisis del Covid-19. Revista Intersecciones; teoría y crítica social.

Grupo Consenso (2015, octubre). Reflexiones sobre los desafíos externos de la Argentina: Seremos afuera lo que seamos adentro. Primer Documento. http://www.cari.org.ar/pdf/documento grupoconsenso.pdf

Haas, R. (2021, 30 de abril). Biden's First Hundred Days. Project Syndicate. https://www.project-syndicate.org/commentary/biden-hundred-days-foreign-policy-continuitywith-trump-by-richard-haass-2021-04

Jeffers, E. A. (2021). The "America First" Trade Policy of the Trump Administration and its Economic and Military Repercussions [Senior Thesis, Liberty University]. Repositorio de la Liberty University https://digitalcommons.liberty.edu/honors/1076/

Johnson, K. y Gramer, R. (2020, 14 de mayo). The Great Decoupling. Foreign Policy. https://foreignpolicy.com/2020/05/14/china-us-pandemic-economy-tensions-trumpcoronavirus-covid-new-cold-war-economics-the-great-decoupling/

Kan, J. y Pascual, R. (2011). Integración regional en América Latina y Argentina ¿Solamente una cuestión de estados? En A. Bonnet (Comp.), El país invisible. Debates sobre la Argentina reciente (pp. 45-80). Peña Lillo; Continente.

La Vanguardia (2021, 20 de enero). Biden reconoce a Guaidó como presidente interino de Venezuela. $\quad$ https://www.lavanguardia.com/internacional/20210120/6185730/eeuuvenezuela-biden-blinken-trump-guaido-maduro-chavismo.html

La Nación. (2021a, 18 de mayo). El plan del Grupo de Puebla para rehabilitar la figura de Nicolás Maduro. https://www.lanacion.com.ar/el-mundo/fue-desapareciendo-una-frase-dealberto-fernandez-sobre-los-ddhh-genero-indignacion-en-venezuela-nid18052021/ 
La política exterior argentina frente al volátil escenario internacional de la postpandemia y la competencia entre

La Nación. (2021ā, 27 de mayo). Lesa humanidad: la Argentina retiró su apoyo a la demanda contra Nicolás Maduro en La Haya. https://www.lanacion.com.ar/politica/delitosde-lesa-humanidad-la-argentina-retiro-su-apoyo-a-la-demanda-contra-nicolas-maduro-en-lahaya-nid26052021/

La Nacion (2019, 4 de julio). El informe Bachelet: la ONU confirma las torturas y ejecuciones en Venezuela. https://www.lanacion.com.ar/el-mundo/el-informe-bachelet-onu-confirmatorturas-ejecuciones-nid2264575/

Lissardy, G. (2021, 29 de abril). El cambio que impulsa Biden en la economía de EE.UU. supone "una ruptura con el neoliberalismo. BBC News Mundo. https://www.bbc.com/mundo/noticias-internacional-56925193

London School of Economics and Political Science (2020). Sustainability impact assessment in support of the Association Agreement Negotiations between the European Union and Mercosur. Final https://trade.ec.europa.eu/doclib/docs/2021/march/tradoc 159509.pdf

Report,

Macri, M. (2016a, 1 de mayo). Palabras del presidente Mauricio Macri en la $134^{\circ}$ apertura de sesiones ordinarias del Congreso. https://www.casarosada.gob.ar/informacion/discursos/35651-palabras-del-presidentemauricio-macri-en-la-134-apertura-de-sesiones-ordinarias-del-congreso

Macri, M. (2016b, 5 de abril). Palabras del Presidente Mauricio Macri en su visita a la fábrica cordobesa de Fiat. https://www.casarosada.gob.ar/informacion/discursos/35928-palabrasdel-presidente-mauricio-macri-en-su-visita-a-la-fabrica-cordobesa-de-fiat

Macri, M. (2017a, 16 de mayo). Mauricio. Palabras del presidente Macri en el Foro de Inversiones $y$ Negocios China - Argentina. https://www.casarosada.gob.ar/informacion/discursos/40680-palabras-del-presidente-macrien-el-foro-de-inversiones-y-negocios-china-argentina

Macri, M. (2017b, 21 de diciembre). Exposición del presidente de la nación, Mauricio Macri, en el 51a cumbre del MERCOSUR y países asociados. https://www.casarosada.gob.ar/informacion/discursos/41525-el-presidente-macri-hablo-enla-51-cumbre-del-mercosur

Macri, M. (2018, 30 de nobiembre). Bienvenida del presidente Mauricio Macri a su par de los Estados Unidos, Donald Trump. https://www.casarosada.gob.ar/informacion/discursos/44286-bienvenida-del-presidentemauricio-macri-a-su-par-de-los-estados-unidos-donald-trump

Macri, M. (2019, 15 de julio). Entrevista al presidente Mauricio Macri / Entrevistador Marcelo Longobardi. https://www.casarosada.gob.ar/informacion/conferencias/45801-entrevista-alpresidente-mauricio-macri-en-cnn-en-espanol.

Malacalza, B. y Hirst, M (2020). ¿Podrá reinventarse el multilateralismo? El orden internacional y el coronavirus. Revista Nueva Sociedad, (287). https://nuso.org/articulo/podra-reinventarse-el-multilateralismo/ 
La política exterior argentina frente al volátil escenario internacional de la postpandemia y la competencia entre China y los Estados Unidos: ¿aquiescencia, pragmatismo o autonomía? DOI: https://doi.org/10.24215/24689912e035

Malamud, A. (2019). Latin America and the World: Dependency, Decoupling, Dispersion. En M. Shifter, y B. Binetti (Eds.) Unfulfilled promises: Latin America Today (107-125). Dialogo Interamericano

Malcorra, S. (2017, 11 de febrero). Declaraciones de la canciller Malcorra. Informe de Prensa 031/17. https://www.cancilleria.gob.ar/es/actualidad/comunicados/declaraciones-dela-canciller-malcorra-0

Marantz, A. (2021, mayo 31). Are We Entering a New Political Era? The New Yorker, American Chronicles. https://www.newyorker.com/magazine/2021/05/31/are-we-entering-anew-political-era

Marchini, J. (2020). América Latina en un marco de crecientes disputas geopolíticas. Cuadernos del pensamiento crítico latinoamericano, (75). https://www.clacso.org/americalatina-en-un-marco-de-crecientes-disputas-geopoliticas/

Miguez, M. C. (2017). Política interna y política exterior en el regionalismo del siglo XXI: conflictos políticos y crisis del MERCOSUR en el Brasil reciente. Informe Integrar (101). http://sedici.unlp.edu.ar/handle/10915/78226

Miguez, M. C. (2020). De Macri a Fernández: dilemas de la Política Internacional Argentina. Revista Sudamérica, https://fh.mdp.edu.ar/revistas/index.php/sudamerica/article/view/4659

(13)80-110.

Ministerio de Relaciones Exteriores, Comercio Internacional y Culto Argentina. (2020a, 12 de diciembre) El Presidente encabezó la firma de cuatro acuerdos con China por USD 4.695 millones para la reactivación de líneas ferroviarias. https://www.cancilleria.gob.ar/es/actualidad/noticias/el-presidente-encabezo-la-firma-decuatro-acuerdos-con-china-por-usd4695\#: :text=El\%20presidente\%20Alberto\%20Fern\%C3\%A1ndez\%20encabez\%C3\%B3,de \%20pasajeros\%20en\%2013\%20provincias.

Ministerio de Relaciones Exteriores, Comercio Internacional y Culto Argentina. (2020b, 06 de julio). Diálogo con el ministro de Comercio de la República Popular China Zhong Shan. https://www.cancilleria.gob.ar/es/actualidad/noticias/dialogo-con-el-ministro-de-comercio-dela-republica-popular-china-zhong-shan

Ministerio de Relaciones Exteriores, Comercio Internacional y Culto Argentina. (2020c, 30 de abril). Mercosur avanzará conjuntamente en la agenda de negociaciones comerciales. Información para la 87 Prensa https://www.cancilleria.gob.ar/es/actualidad/noticias/mercosur-avanzara-conjuntamente-enla-agenda-de-negociaciones-comerciales

Okonjo-Iweala, N. (2020, 22 de junio). Reviving the WTO. Project Syndicate, https://www.project-syndicate.org/commentary/reviving-the-world-trade-organization-byngozi-okonjo-iweala-2020-06?barrier=accesspaylog

Orr, G. (2018). What can we expect in China in 2019? McKinsey \& Compañy https://www.mckinsey.com/featured-insights/china/what-can-we-expect-in-china-in-2019 
La política exterior argentina frente al volátil escenario internacional de la postpandemia y la competencia entre China y los Estados Unidos: ¿aquiescencia, pragmatismo o autonomía? DOI: https://doi.org/10.24215/24689912e035

Página 12. (2020, 21 de octubre). Alberto Fernández llamó a reconstruir la Unasur: "Es lo que más le conviene a América Latina". https://www.pagina12.com.ar/300680-albertofernandez-llamo-a-reconstruir-la-unasur-es-lo-que-ma

Paikin, D. (2018). Impacto del multilateralismo indefinido sobre las relaciones comerciales de la Argentina. Documento de Trabajo del CENES, (25), 1-25. http://www.economicas.uba.ar/wp-content/uploads/2016/03/CENES-25-revisado.pdf

Panitch, L. y Gindin, S. (2015). La construcción del capitalismo global: La economía política del imperio estadounidense. Ediciones Akal.

Pascual, R.y Ghiotto, L. (2019). La política exterior de Macri: la ofensiva contra el trabajo de cara al mundo. En P. Belloni, y Cantamutto, F. (Coords.), La economía política de Cambiemos. Ensayos sobre un nuevo ciclo neoliberal en la Argentina (pp. 59-87). Batalla de Ideas.

Pignatta, E. (2020). Política internacional latinoamericana, cambios de ciclo y agenda regional en la coyuntura de pandemia. En A. Busso (Comp.), Relaciones Internacionales en tiempos de Pandemia (pp. 170-177). Centro de Investigaciones en Política y Economía Internacional. Universidad de Rosario. http://hdl.handle.net/2133/18304

Polanyi, K. (2011). La gran transformación: crítica del liberalismo económico. Fondo de Cultura Económica.

Posen, A. (2021, mayo/junio). The Price of Nostalgia. America's Self-Defeating Economic Retreat. Foreign Affairs. https://www.foreignaffairs.com/articles/united-states/2021-0420/america-price-nostalgia

Rocha Valencia, A. (2021). Orden político e integración regional en América Latina: del avance autónomo a la regresión heterónoma (2000-2019) En A. Rocha Valencia y J. E. Tamayo Rodríguez, (Coords.), Gobiernos progresistas y gobiernos conservadores en América Latina del Siglo XXI (pp. 19-36). Universidad de Guadalajara,

Rodríguez, M. y Touzon, P. (2020, abril). La que tocó. Le Monde Diplomatique, (250). https://www.eldiplo.org/250-ya-nada-sera-como-antes/la-que-toco/

Roubini, N. (2020). The specter of deglobalization and the Thucydides trap. Horizons, (15). https://www.cirsd.org/en/horizons/horizons-winter-2020-issue-no-15/the-specter-ofdeglobalization-and-the-thucydides-trap

Rousset, P. (2018, 1 de julio). Géopolitique chinoise: continuités, inflexions, incertitudes. Europe Solidaire Sans Frontieres, http://www.europe-solidaire.org/spip.php?article45040.

Russell, R. y Tokatlian, J. G. (2013). América Latina y su gran estrategia: entre la aquiescencia y la autonomía. Revista Cidob d'afers internacionals, (104), 157-180. https://www.cidob.org/articulos/revista cidob d afers internacionals/104/america latina y su gran estrategia entre la aquiescencia y la autonomia

Sanahuja, J. A. (2020). ¿Bipolaridad en ascenso? Análisis equívocos frente a la crisis de la globalización. Foreign Affairs Latinoamérica, 20(2). https://eprints.ucm.es/id/eprint/59924/ 
La política exterior argentina frente al volátil escenario internacional de la postpandemia y la competencia entre China y los Estados Unidos: ¿aquiescencia, pragmatismo o autonomía? DOI: https://doi.org/10.24215/24689912e035

Simonoff, A. (2016). Los nuevos senderos de las discusiones teóricas conosureñas: globalistas, neo-estructuralistas y lecturas críticas. Relaciones Internacionales, 25(50). http://www.iri.edu.ar/index.php/2016/07/04/revista-relaciones-internacionales-no-50segmento-digital/

Simonoff, A. (2017). Inserción argentina en los inicios de la era Trump. Revista de Relaciones Internacionales, (52), $\quad 1-9$ http://sedici.unlp.edu.ar/bitstream/handle/10915/61606/Documento completo.pdf?sequence $=1$ \&isAllowed $=\mathrm{y}$

Simonoff, A. (2020). Argentina en el mundo: ¿ldas y vueltas? Cadernos de Campo: Revista de Ciências Sociais, (29). https://redib.org/Record/oai articulo3114018-argentina-worldgoing-back-forth

Smith, A. (2018, 22 de octubre) The road to a new cold war with China. Socialist Worker, https://socialistworker.org/2018/10/22/the-road-to-a-new-cold-war-with-china

Solá, F. (2020, 9 de mayo). Un Mercosur fuerte y sin dogmas. Diario Clarín. https://www.clarin.com/opinion/mercosur-fuerte-dogmas 0 trKxXkn5l.html

Solá, F. (2021, 1 de marzo). Felipe Solá: "Alberto Fernández dejó en claro que la Argentina se integra al mundo con la frente en alto y no de rodillas". Información para la Prensa 55/21. https://www.cancilleria.gob.ar/es/actualidad/noticias/felipe-sola-alberto-fernandez-dejo-enclaro-que-la-argentina-se-integra-al-mundo

Taglioni, A. (2021, 1 de enero). Cinco claves de la política exterior de Alberto de cara al 2021: Malvinas, Mercosur y FMl". El Canciller, https://elcanciller.com/opinion/cinco-clavesde-la-politica-exterior-de-alberto-para-2021

The Economist (2020, 14 de mayo). Globalisation unwound: Has covid-19 killed globalisation?

globalisation https://www.economist.com/leaders/2020/05/14/has-covid-19-killed-

Tokatlian, J. G. (2019, 1 de diciembre). Los desafíos por delante serán monumentales /Entrevistador Juan Elman. Cenital. https://www.cenital.com/tokatlian-los-desafios-pordelante-seran-monumentales/

Tokatlian, J. G. (2020, 1 de mayo 2020). Se percibe un vacío de liderazgo en Latinoamérica Entrevistador/Jorge Fontevecchia. Diario Perfil. https://www.perfil.com/noticias/periodismopuro/se-percibe-un-vacio-de-liderazgo-enlatinoamerica.phtml

Touzon, P. (2020, mayo). Salir de la Matrix ¿Dejará algún saldo positivo la pandemia? Parte I, Le Monde Diplomatique. https://www.eldiplo.org/notas-web/salir-de-la-matrix/

Traverso, E. (2020, 5 de abril). El estado de emergencia sanitaria corre el riesgo de ejercer un control total sobre nuestras vidas /Entrevistador Mathieu Dejean. Viento Sur. https://vientosur.info/el-estado-de-emergencia-sanitaria-corre-el-riesgo-de-ejercer-uncontrol-total/ 
La política exterior argentina frente al volátil escenario internacional de la postpandemia y la competencia entre

Treacy, M. (2021). Great chaos under heaven: strategies and challenges for consolidating China's global hegemony in the 21st Century. En C. Shei, (Comp.), The Routledge Handbook of Chinese Studies. Routledge

UNCTAD (2020). Informe sobre las inversiones en el mundo 2020. La producción internacional después de la pandemia. Naciones Unidas. https://unctad.org/system/files/official-document/wir2020 overview es.pdf

UNCTAD (2021). Global Trade Update. United Nations UNCTAD. https://unctad.org/system/files/official-document/ditcinf2021d1 en.pdf

Ward, A. (2021, 22 de enero). Biden plans to continue many of Trump's foreign policies - at least for now. Vox, https://www.vox.com/22244427/biden-trump-foreign-policy-presidencyinauguration

Woodward, J. (2017). The US Vs China: Asia's New Cold War? Manchester University Press.

Zhao, M. (2019). Is a New Cold War Inevitable? Chinese Perspectives on US-China Strategic Competition. The Chinese Journal of International Politics, 12(3), 371-394. https://academic.oup.com/cjip/article/12/3/371/5544745

Zelicovich, J. y Egea Dellarda, I. (2020, 25 de junio). El mundo post pandemia comienza a definirse en la OMC. Diario Perfil. https://www.perfil.com/noticias/internacional/el-mundopost-pandemia-comienza-a-definirse-en-la-omc.phtml

Zelicovich, J. y Romero, C. (2020). El impacto del COVID-19 en las relaciones comerciales internacionales. En Busso, A. (Comp.), Relaciones Internacionales en tiempos de Pandemia. Centro de Investigaciones en Política y Economía Internacional (CIPEI).

MARIANo TrEacy: Doctor en Ciencias Sociales por la Universidad de Buenos Aires (UBA). Profesor Adjunto e Investigador del Instituto del Desarrollo Humano de la Universidad Nacional de General Sarmiento (UNGS), Instituto del Desarrollo Humano. Correo electrónico: mtreacy@campus.ungs.edu.ar; ORCID ID: https://orcid.org/0000-0002-1516-6076. 